\title{
Indentation of the Philippine Sea plate by the Eurasia plate in Taiwan: Details from recent marine seismological experiments
}

\author{
Serge Lallemand ${ }^{a, b, *}$, Thomas Theunissen ${ }^{c}$, Philippe Schnürle ${ }^{d}$, Chao-Shing Lee ${ }^{b, e}$, \\ Char-Shine Liu ${ }^{\text {b, }}$, Yvonne Font ${ }^{g}$
}

\author{
a Géosciences Montpellier, Université Montpellier 2, CNRS, place E. Bataillon, 34095 Montpellier cedex 05, \\ France \\ ${ }^{b}$ LIA ADEPT, France, Taiwan \\ c IRAP, Observatoire Midi-Pyrénées, Toulouse, France \\ d Géosciences Marines, IFREMER, Plouzané, France \\ e Applied Geophysics, NTOU, Keelung, Taiwan \\ ${ }^{\mathrm{f}}$ Institute of Oceanography, NTU, Taipei, Taiwan \\ ${ }^{g}$ Université de Nice Sophia-Antipolis, Institut de Recherche pour le Développement, Observatoire de la Côte \\ d'Azur, Géoazur, France \\ *: Corresponding author : Serge Lallemand, tel.: + 33467143301 ; fax: + 33467143642 ; \\ email address : lallem@gm.univ-montp2.fr \\ thomas.theunissen@irap.omp.eu ; Philippe.Schnurle@ifremer.fr ; leecs@mail.ntou.edu.tw ; csliu@ntu.edu.tw ; \\ font@geoazur.obs-vifr.fr
}

\begin{abstract}
:
We analyze in this study a new set of marine data including 3D local tomography, 1992-2008 relocated earthquakes and two recent multichannel seismic lines to characterize the deformation style in the collision area offshore east Taiwan. We have mapped in detail the Mohos of the converging plates as well as the subduction interface with a resolution never reached before. We show that the sharp continental subduction of the Eurasia plate, beneath the middle part of the Central Range, indents the Philippine Sea plate (PSP) as attested by intra-oceanic slicing and incipient subduction of the PSP beneath the east coast of Taiwan. The westernmost part of the PSP slab is probably experiencing a beginning of break-off as attested by NW-trending en-échelon shear zones beneath the southern slope of the southern Ryukyu arc (SRA). These en-échelon shear zones have a sinistral component favored by the "collision-free" subduction of the PSP north of $24^{\circ} 30^{\prime} \mathrm{N}$. The down-faulting of the subduction interface forms ramps along which earthquakes clusterize. Three M7 subduction earthquakes occurred offshore Suao city along these ramps with a recurrence interval of about 40 years: $1920 M_{w} 7.7,1963 M_{w} 7.2$ and $2002 M_{w} 7.1$ events. The $1966 M_{w} 6.0-7.5$ earthquakes sequence likely outlines a WNW-ESE left-lateral intra-slab shear zone. The SRA upper plate accommodates the complex geometry and deformation of the subducting PSP through seismic deformation. Shallow high velocities fringing the Luzon volcanic arc (LVA) beneath the Longitudinal Valley and north of the southernmost Ryukyu forearc basins are interpreted as relics of the LVA forearc basement squeezed in the collision zone. Based on the accommodation of a large part of the convergence through shortening within the PSP and the subsequent segmentation of the shallow subduction interface, we consider that the nucleation of a $\mathrm{M}_{\mathrm{w}} \geq 8$ earthquake along the southernmost Ryukyu megathrust is unlikely.
\end{abstract}




\section{Highlights}

- We have mapped the Mohos and plates interface in NE Taiwan with a resolution never reached before $>$ Today, the Eurasia plate indents the Philippine Sea plate in central Taiwan $>$ The subducting Philippine Sea plate undergoes intra-oceanic slicing and tearing Subduction earthquakes clusterize on ramps of the subducting Philippine Sea plate The nucleation of a Mw $\geq 8$ earthquake along the southernmost Ryukyu megathrust is unlikely

Keywords: Arc-continent collision ; Local tomography ; Tear, subduction ; Intra-oceanic slicing ; Slab break-off

\section{Introduction}

Taiwan represents one of the youngest and most-studied collisional belt in the world (Angelier et al., 1986, Angelier et al., 1990, Biq, 1972, Chai, 1972, Chemenda et al., 1997, Ho, 1986, Huang et al., 2006, Lallemand et al., 2001, Lu and Hsu, 1992, Malavieille and Trullenque, 2009, Malavieille et al., 2002, Sibuet and Hsu, 2004, Suppe, 1981, Suppe, 1984, Teng, 1990, Teng, 1996, Teng et al., 2000, Tsai, 1986, Wu, 1970, Wu, 1978 and Wu et al., 1997). The orogen results from the oblique southeastward subduction of the South China Sea (SCS) rifted margin beneath the northern prolongation of the Luzon volcanic arc (LVA) carried by the Philippine Sea plate (PSP). This view reasonably accounts for the geological observations south of $23^{\circ} \mathrm{N}$ (i.e., southern third of the island), but north of $23^{\circ} \mathrm{N}$, singular features add complexities to this simple setting. First of all, the eastward continental subduction of Eurasia plate (EP) beneath the PSP is orthogonal with the southern 
Ryukyu subduction system where the PSP subducts northward beneath the EP, both plates interacting at depth beneath the northeastern part of Taiwan island. Secondly, the southern Ryukyu arc (SRA) is presently rifting, resulting in a rapid southward migration of the arc-trench system with respect to the EP (Chinese platform). A large part of this collisional area north of $23^{\circ} \mathrm{N}$ is submerged below deep waters so that its investigation requires marine facilities. Tremendous work has been done since the eighties but the intensity of the deformation encountered east of Taiwan is so high that the geophysical images were unclear and left to contrasting interpretations (e.g., Font et Lallemand, 2009).

To better illuminate the structure and the microseismicity of this complex region, we have conducted a series of local seismological cruises in the frame of the "Ryukyu Arc Tectonics and Seismology" (RATS) Project ${ }^{2}$ conducted in parallel with the regional TAIGER Project ${ }^{3}$ (Wu et al, 2007b). Preliminary results were published by Klingelhoefer et al. (2012) and Theunissen et al. (2012a). The RATS data allowed us to relocate past seismic events in the region within a new 3D velocity model, giving way to a revised geodynamic interpretation of the region.

Based on the new 3D velocity model and earthquakes relocation, as well as two new multichannel seismic lines, the remaining questions that we address in this study are the following : how does the PSP accommodate the increasing shortening from south to north offshore Taiwan? how are the eastern part of Taiwan and the SRA affected by this deformation? and what is the potential for a great subduction earthquake along the southernmost Ryukyu subduction interface?

\section{2- Geodynamic context and previous work}

\section{1 - Kinematics}

The Taiwan mountain belt build up over the « quasi-stationary » (with respect to hotspots) subducting continental lithosphere of the EP. The buttress, against which the orogen grows by addition of crustal units in the foreland, consists of the deformed volcanic edge of the overriding PSP. Near $23^{\circ} \mathrm{N}$, two-third of the $8 \mathrm{~cm} / \mathrm{yr}$ of shortening mainly localizes along the thrust deformation front near the western coast of the island and the steeply dipping thrust of the Longitudinal Valley that separates the indenting northern LVA from the growing orogen (Yu et al., 1997)(Fig.1). The rest of the shortening must be accommodated offshore (Malavieille et al., 2002; Simoes et Avouac, 2006; Huang et al., 2010). Near $24^{\circ} \mathrm{N}$, one-third or less of the convergence between the EP and the PSP is accommodated on the island mainly in the Longitudinal Valley. North of $24^{\circ} \mathrm{N}$, GPS measurements indicate block rotations and southeastward extrusion (Yu et al., 1997; Rau et al., 2008; Hou et al., 2009; Hsu et al., 2009; Lin et al., 2010 ) that necessitates to account for more than $8 \mathrm{~cm} / \mathrm{yr}$ of convergence offshore. The most prominent offshore expression of convergence north of $24^{\circ} \mathrm{N}$ is undoubtely the WNW-ESE trending southern Ryukyu accretionary wedge, which strikes almost parallel to the direction of EP-PSP convergence (N307 ${ }^{\circ}$, Seno et al., 1993), and thus can not be the expression of NW-SE compression. Recent GPS measurements indicate a southward drift of the SRA Japanese islands reaching up to $7 \mathrm{~cm} / \mathrm{yr}$ in Yonaguni (Nakamura, 2004; Nishimura et al., 2004) which makes the convergence in the Ryukyu trench much less oblique and implies a rapid southward trench roll back (Fig.1). Such motions are very recent since the amount of N-S extension in the southern Okinawa Trough (SOT) has been estimated to $80 \mathrm{~km}$ in the last $2 \mathrm{Myr}$, i.e., about $4 \mathrm{~cm} / \mathrm{yr}$ in average (Kimura, 1985; Letouzey and Kimura, 1986; Sibuet et al., 1998). One would expect N-S transform zones cutting through the arc to accommodate its soutward drift, especially near Taiwan as searched by Lallemand and Liu (1998) or later by Lallemand et al. (1999) but most marine investigations in this sense were unsuccessfull except some indications in the Hoping Basin (Font et al., 2001). Kinematic studies have also shown that the motion of the PSP was more northward or even northeastward before 5 or 8 Ma ago (Seno and Maruyama, 1984; Hall

\footnotetext{
2 The RATS Project is part of the Active Tectonics and Seismic Hazard in Taiwan (ACTS) French ANR program

${ }^{3}$ TAIGER : TAiwan Integrated GEodynamic Research project between US and Taiwanese teams.
} 
et al., 1995; Faccenna et al., 2009). Lallemand et al. (2001) have proposed that this motion change contributed in the westward migration of the Ryukyu trench across a propagating tear within the EP. The corollary of this is that the present SRA constituted the northern passive margin of the (now subducted) SCS prior to the westward migration of the Ryukyu trench (Fig.2). The former northward motion of the PSP along its western convergent boundary is probably responsible for the steepness of the subducting SCS as seen on global tomographic sections (Lallemand et al., 2001) despite the rapid rollback that the Manila trench encounters since the change of plate motion. Indeed, highly oblique subduction zones such as Andaman, West Aleutian or South-Mariana are all associated with steep slabs.

The revised subduction obliquity along the southern Ryukyu trench, that accounts for the southward drift of the SRA, is still of the order of $50^{\circ}$ with respect to trench normal west of $122^{\circ} 40^{\prime} \mathrm{E}$. The revised subduction rate in the direction of convergence presently reaches 14 $\mathrm{cm} / \mathrm{yr}$ with a trench-normal component of $9.3 \mathrm{~cm} / \mathrm{yr}$ and a trench-parallel component of 10.5 $\mathrm{cm} / \mathrm{yr}$. Previous studies have shown that the high subduction obliquity was responsible for trench-parallel stretching within the forearc basins and strain partitioning at the scale of the accretionary wedge (Lallemand et al., 1999). No strain partitioning at the scale of the SRA basement was evidenced yet as previously suggested by Kao et al. (1998). Instead of that, WNWESE sinistral transcurrent faulting was evidenced during the 1966 seismic crisis that included one $\mathrm{M}_{\mathrm{w}} 7.5$ earthquake and three $6.0 \leq \mathrm{M}_{\mathrm{w}} \leq 6.2$ aftershocks occurring below the south-facing Ryukyu arc slope southwest of Yonaguni island (Wu, 1978) whereas dextral strike-slip faulting is expected in case of strain partitioning compatible with the present subduction obliquity. All four events aligned along the NW-SE left-lateral nodal plane (see Fig.1).

\section{2 - Seismicity}

The seismicity rate is extremely high on, or east and south of, Taiwan even if no historical $\mathrm{M}_{\mathrm{w}} 8$ earthquake was recorded by the local seismic network (Theunissen et al., 2010). In 1998, Kao, based on a study of historical earthquakes, said that it was inconclusive whether a $M>8$ event may occur or not in and around Taiwan. In terms of distribution, both Benioff zones are clearly visible east of $121^{\circ} 30^{\prime} \mathrm{E}$ for the PSP slab and south of $23^{\circ} \mathrm{N}$ for the SCS slab. Many authors consider that the SCS slab, despite the absence of Benioff zones north of $23^{\circ} \mathrm{N}$, still extends until at least $24^{\circ} \mathrm{N}$ (Fig.2) or even more northward, based on global or local tomography (Wu et al., 1997; Wang et al., 2006; Lallemand et al., 2001 ; Ustaszewski et al., 2012). Seismicity concentrates in some very active areas such as the Foothills in the western part of the orogen (e.g., $1999 \mathrm{M}_{\mathrm{w}} 7.6$ Chichi Earthquake), the Coastal Range which is an extinct segment of the LVA colliding with the orogen (e.g., $1951 \mathrm{M}_{\mathrm{w}} 7$ earthquakes triplet), the coastal region north of the Coastal Range is also extremely seismic as well as the E-W-trending South Okinawa rift valley near $24^{\circ} 45^{\prime} \mathrm{N}$. One puzzling feature is the clustering of earthquakes in the SRA forearc. Instead of showing a classical pattern of seismogenic zone extending from $\approx 10-20 \mathrm{~km}$ to $\approx 50-60 \mathrm{~km}$ depths (e.g., Peacock and Hyndman, 1999, Heuret et al., 2011), we observe a concentration of earthquakes at shallow depths below the forearc basins. Font and Lallemand (2009) have studied in detail this region by relocating events taking advantage of a new code and 3D velocity model (MAXI; Font et al., 2004) and the joint use of Taiwanese and Japanese land stations. They succeeded to better locate the epicenters of the events but were unsuccessfull in determining accurate depths using only land stations far from the sources. The largest magnitude earthquake never recorded in Taiwan $\left(M_{w} 7.7\right)$ occurred within this cluster (Theunissen et al., 2010) that comprises mostly shallow northward dipping thrust faults (Kao et al., 1998). The stress pattern, inversed from focal mechanisms of crustal earthquakes in the region northeast of Taiwan, is complex (Wu et al., 2010a; Wu et al., 2010b; Huang et al., 2012). E-W intra-PSP compression is observed in many places offshore the northern Coastal Range (e.g., $1967 \mathrm{M}_{\mathrm{w}} 6.8$ or $1986 \mathrm{M}_{\mathrm{w}} 7.3$ events) as well as strike-slip (see 1966 events described above and Fig.1) or normal faulting compatible with E-W extension (e.g., $2001 \mathrm{M}_{\mathrm{w}} 6.8$ event). The diversity of focal mechanisms results from the complex 3D interaction of three plates (EP, PSP, SRA) including collision, subduction and rifting (Fig.1). Deciphering between structural units involved first requires to map the plates interfaces in depth. 


\section{3 - Geology of PSP, SRA and Taiwan East coast}

The study area includes three domains s.s. : the Huatung basin, the eastern coast of Taiwan and the southern Ryukyu forearc (Fig.1 \& 3).

The Huatung basin is an oceanic domain, about $120 \mathrm{~km}$ wide, lying between the LVA to the west and the Gagua Ridge to the east. It subducts to the north beneath the SRA along the Ryukyu trench. The origin and age of this basin is controversed but samples dredged on basement highs suggest an Early Cretaceous age for the crust (Deschamps et al., 2000). Its mean depth is $400 \mathrm{~m}$ shallower than expected for an oceanic crust of that age (Deschamps et al., 1998). The crust is loaded by sediments, up to $2 \mathrm{~km}$ thick on edges, mostly supplied from the nearby growing orogen. Furthermore, refraction profiles indicated that the crustal thickness was about $12 \mathrm{~km}$ (McIntosh and Nakamura, 1998) revealing some possible excess of magmatism during its creation. Reflection seismics and gravity modeling both shows a flexure of the basin under the load of the LVA on one side and the Gagua Ridge on the other (Deschamps et al., 1998). The origin of this old piece of oceanic crust, separated from the Eocene West Philippine Basin by the N-S trending Gagua Ridge, remains unknown. The age contrast on both sides of the Gagua Ridge and its linearity argue in favor of an old transform zone uplifted during a plate reorganisation in the mid-Eocene (Deschamps et al., 1998). During the compressional event, part of the adjacent basin was probably subducted. The ridge now culminates at about $4 \mathrm{~km}$ above the surrounding seafloor.

The structure and nature of the eastern coast of Taiwan varies from south to north. South of $22^{\circ} 40^{\prime} \mathrm{N}$, the growing crustal accretionary wedge is exposed along the coast. The extinct LVA parallels the coast on the east at a distance narrowing from $60 \mathrm{~km}$ in the south (Lanyu island) to $30 \mathrm{~km}$ at the latitute of Taitung (Lutao island). Between $22^{\circ} 40^{\prime} \mathrm{N}$ and $24^{\circ} \mathrm{N}$, the LVA appears fully submerged except in some small places where it outcrops on the Coastal Range (e.g., Chimei edifice). The Coastal Range itself mainly consists of intra- or fore-arc volcano-sedimentary basins that have been shortened during the arc-continent collision (Huang et al., 1992). It overthrusts the Longitudinal Valley to the west that lies at the foot of the Central Range, i.e., the innermost unit of the orogen. North of Hualien $\left(24^{\circ} \mathrm{N}\right)$, the metamorphic Central Range directly outcrops along the shore, where unstable flanks collapse into the $3000 \mathrm{~m}$ deep Hoping Basin. North of that, near $24^{\circ} 45^{\prime} \mathrm{N}$, the triangular flat Ilan Plain corresponds to the westernmost termination of the SOT propagating rift, attesting for an abrupt change of the tectonic regime from compression south of $24^{\circ} 35^{\prime} \mathrm{N}$ to extension north of that (Lu et al., 1995). Kueishan Tao (Turtle island), located $10 \mathrm{~km}$ offshore Ilan (Fig.1), is an island arc volcano lying right in the E-W trending axis of the rift, with a chemistry which differs from subduction basalts (R. Shinjo, personnal comm.).

The SRA elongates along an E-W direction, south of the SOT and east of the NE Taiwan coast. It consists of a presently non-volcanic arc on which a few islands rise above sea-level such as the small Yonaguni island and the largest Iri-Omote island (see Fig.1) where 13 Ma old OIB-type high-Mg andesites outcrop (R. Shinjo, personnal comm.). Yonaguni island is mostly composed of tabular upper Pleistocene Ryukyu limestone and Holocene raised reef limestone lying on lower to middle Miocene sandstones and siltstones of the Yaeyama Group. Most of Iri-Omote island is covered by the Yaeyama Group but there, the Triassic and Jurassic metamorphic basement outcrops in the eastern part of the island as it also does in the other islands of the Ryukyus (Ishigaki, Miyako) (Fabbri and Fournier, 1999). South of the arc, a series of forearc basins align back of a well-developped sedimentary accretionary wedge (Lallemand et al., 1999). The basement below the forearc basins is characterized by lows (e.g., $10 \mathrm{~km}$ deep "hole" $50 \mathrm{~km}$ off Hualien) and highs (promontories) with an amplitude of at least $2 \mathrm{~km}$ (Font et al., 2001). One of these basement promontories : the Nanao rise, has been attributed to an uplift caused by the subducting Gagua Ridge whereas another one : the Hoping rise, closer to Taiwan, is not explained yet. The Ryukyu arc basement ends abruptly at the transition between the forearc basins and the accretionary wedge as first proposed by Font et al. (2001) and later supported by wide-angle refraction data (Klingelhoefer et al., 2012). According to geodynamic reconstructions, 
the forearc basins and the accretionary wedge are probably no older than a few million years in

\section{3- New results from RATS experiments}

\section{1 - The RATS experiment}

A passive experiment was first conducted in 2008 using 22 ocean bottom seismometers (15 short-period and 7 broadband OBS) and 51 inland seismic stations which have recorded the microseismicity during three months from July 19 to October 24. Then, an active experiment (wide-angle and coincident reflection seismics) occurred in May 2009 using 24 short-period OBS aligned across the SRA system, $6600 \mathrm{inch}^{3}$ seismic sources and a $6 \mathrm{~km}$ long streamer of the US $\mathrm{R} / \mathrm{V}$ Marcus Langseth. Given the distribution of Taiwanese and Japanese land seismic stations with respect to the active seismic zones, the passive OBS array was deployed in the forearc area of the SRA on both sides of the active line (see Fig.3).

\section{2 - The active 2D line through the Ryukyu arc}

The active line has been set to cross the major seismic cluster observed in the forearc area of the SRA, i.e., the Hoping cluster (located beneath the Hoping Rise - see Figs.1 \& 4). The main outcomes of the velocity structure along this line (Klingelhoefer et al., 2012) are (1) the presence of a rather thin (5-6 km) subducting oceanic crust overlying a "low-velocity » mantle $(7.8 \mathrm{~km} / \mathrm{s})$ supposed to be hydrated by hydrothermalism, (2) the low velocities associated with the accretionary wedge can be traced back to the Nanao forearc basin, resulting in an abrupt termination of the SRA basement, (3) a low velocity zone has been detected between the base of the SRA basement and the subducting PSP, and (4) the SRA Moho where the active line crosses has been detected at a depth of about $25 \mathrm{~km}$.

\section{3 - The passive experiment: a new 3D velocity model}


This velocity section together with other velocity data in the region were used to build a 3D a priori P-wave velocity model, used itself as initial velocity model for the joint $\mathrm{P}$ and S-waves velocities inversion with about 1000 micro-earthquakes hypocenters recorded during the passive experiment (Theunissen et al., 2012a). Our 3D tomographic model results from an inversion within a $10 \times 10 \times 6 \mathrm{~km}^{3}$ grid further interpolated into a $1 \times 1 \times 1 \mathrm{~km}^{3}$ grid in order to calculate travel-times and to draw tomographic images. This last interpolation induces a maximum uncertainty equal to the initial grid size, i.e., $6 \mathrm{~km}$ in vertical and $10 \mathrm{~km}$ in horizontal at the most. Checkerboard tests revealed that the dataset, both with P- or S-wave, is able to reconstruct in shape $20 \times 20 \times 12 \mathrm{~km}^{3}$ and $30 \times 30 \times 12 \mathrm{~km}^{3}$ pattern velocity anomalies in the target area, below the OBS network and to the west at the transition with Taiwan, down to a depth of about 40-50 km. Finally, using the new 3D tomography together with the OBS data greatly improves the hypocenter determination, especially in depth.

\section{4 - Relocation of earthquakes (1992-2008 $\mathrm{M} \geq 3)$}

The new 3D velocity model has been tested without the use of the OBS for locating 77 reference events well-located during the 3 months of deployment thanks to the new version of the MAXIcode (Font et al., 2004 ; Theunissen et al., 2012b). The tests show that it greatly improves the location of the hypocenters in the studied region (Theunissen et al., 2012a). In this study, we have relocated all $M \geq 3$ events that were recorded both by the Taiwanese seismological network (CWB for Central Weather Bureau) and the Japanese one (JMA for Japan Meteorological Agency) during the period 1992-2008. We have applied the following procedure :

(1) In the area $121^{\circ} \mathrm{E}-124.4^{\circ} \mathrm{E}, 22^{\circ} \mathrm{N}-25.3^{\circ} \mathrm{N}$, a total of $11,475 \mathrm{M}_{\mathrm{L}} \geq 3$ events were selected from picking catalogs of both JMA and CWB satisfying the criteria to have been detected by at least one JMA and two CWB stations. For this initial catalog, the number of Pmeasurements is, in average, $21 \pm 6$ of which $16 \pm 6$ from the CWB and $5 \pm 1$ from the JMA.

(2) In order to avoid uncertainties in the S-arrival-times and associated velocity model inherent to the geometry of our seismic network (the distance between an event and the nearest station may be large), we have only used P-arrival-times (Font et al., 2004; Font et al., 2013). Ptravel-times tables are calculated within the new 3D velocity model using the Shortest Path

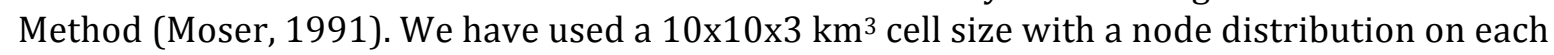
facet every $1 \mathrm{~km}$ in depth and $2 \mathrm{~km}$ in horizontal.

(3) We then applied the MAXI algorithm (Theunissen et al., 2012b) to realize the absolute earthquake location allowing the use of only P phases. Solutions are sorted according to confidence factors based on MAXI algorithm (our estimated uncertainty is $\pm 8.0 \mathrm{~km}$ in depth and $\pm 4 \mathrm{~km}$ in horizontal in average $(+1 \sigma)$ ) rather than rms error $\left(X^{2}\right.$ uncertainty is $\pm 4.0 \mathrm{~km}$ in depth and $\pm 1.8 \mathrm{~km}$ in horizontal in average $(+1 \sigma)$ ) (see appendix for further details).

(4) Finally, 5996 earthquakes, recorded by $22 \pm 6$ phases in average, have been selected and are used to build images (Fig.4) and make interpretations. Our relocated depths are, on average, $4.4 \mathrm{~km}$ deeper than those of CWB but with large variations from place to place (see appendix for further details). Two regions show opposite tendencies, i.e., shallower locations : the Nanao cluster and the rift zone (see Fig.S1 in Appendix).

These results are in agreement with the shallow seismic activity in the upper crust at these locations (Konstantinou et al., 2011; Lin et al., 2008) and the deeper one in the other areas and especially in the southern Ryukyu forearc region. The comparison of our results and hypocenters determined by the CWB for 27 events associated with well-determined focal mechanisms (see Table 1 for sources), along three reference sections across the Southern Ryukyu forearc system (Fig.5, see location on Fig.4), shows a seismicty pattern that is more clustered and in better agreement with the expected geodynamics of this region. For example, the Hoping seismic cluster (HC in Fig.4), that was initially located in the upper plate in the previous studies (Kao et al., 1998; Font and Lallemand, 2009), now mainly concentrates in the vicinity of the plates interface (Fig.5). Furthermore, we verify that focal mechanisms better 
agree with the overall subduction context with most subduction-thrust events locating in the upper part of the subducting crust or along the plate interface and the other events showing slab lateral compression at depths larger than $40 \mathrm{~km}$ in the uppermost lithospheric mantle as previously mentionned by Kao et al. (1998). Details on focal mechanisms are given in Table 1. When different focal solutions were available for a single event, our selection priority order was : (1) Kao et al. (1998), (2) CMT Harvard, (3) BATS (Kao and Jian, 1999) for most earthquakes except three old events in 1951 (Cheng et al., 1996) and in 1963 (Chen et al., 2004).

We will now discuss these new results and integrate them into a comprehensive geodynamic model.

\section{4- Revised plates geometries based on the new 3D local tomography}

In this study, we obtain a local tomography in the triangular area between Chengkung $(50 \mathrm{~km}$ north of Taitung), Ilan and Iri-Omote (see Fig.1) that undergoes the maximum strain caused by arc-continent collision. The density of onland and offshore seismic stations during the RATS experiments has allowed to achieve a much better resolution than previous studies for shallow levels, decreasing in size in depth (see Fig.6).

The main challenge in this complex region is the discrimination between EP and PSP in the area of interaction, i.e., the collision and subduction interfaces, which are partly located offshore where deep seismic imagery was not reliable before the TAIGER and RATS experiments. We will first point out the main differences of our new dataset with those already published (Rau and Wu, 1995 ; Lin et al., 2004 ; Kim et al., 2005, 2006 ; Wu et al., 2007a ; Wang et al., 2006 ; Wu et al., 2009a\&b ; Kuo-Chen et al., 2012; Ustaszewski et al., 2012) and then examine the various structural domains. All tomographic models have used local earthquakes recorded by CWB and sometimes combined with JMA stations. A few of them have used teleseismic events in addition to local events. Those who have used OBS data get better resolution in the areas where OBS are deployed compared with others like Lin et al. (2004) for example in the SOT or Wu et al. (2009b) in the area offshore SW Taiwan, but only Kuo-Chen et al. (2012) have used a large number of OBS deployed all around the island during more than a year. Those OBS were scarcely spaced on the seafloor whereas those of the RATS experiment were quite dense in the southern Ryukyu forearc area.

Tomographic models generally show a thicker (up to 50 or even $60 \mathrm{~km}$ ) crustal root beneath the Central range near $24^{\circ} \mathrm{N}$ that extends from $23^{\circ} 20^{\prime} \mathrm{N}$ to $24^{\circ} 50^{\prime} \mathrm{N}$ (Rau and $\mathrm{Wu}, 1995$; Wu et al., 2007a; Kuo-Chen et al., 2012). The map of the « Moho » on Figure 7 has been drawned from our new 3D tomographic model. The sudden increase in the velocity gradient, near $7.5 \mathrm{~km} / \mathrm{s}$ beneath the Huatung Basin and $7.75 \mathrm{~km} / \mathrm{s}$ beneath the SRA, helped to constrain Moho's depth. We have used $7.5 \mathrm{~km} / \mathrm{s}$ for the PSP and $7.75 \mathrm{~km} / \mathrm{s}$ for the EP and SRA as isovelocities to pick the respective Mohos. One difficulty when drawing the Moho depth map is that the Mohos of the EP and the PSP overlap in areas like beneath the Coastal Range or the SRA. We were thus very cautious with the data using seriated vertical sections (like those shown in Figs.8\&9) in order to pick the right plate for a given « Moho » surface. We have accurately picked the seaward limit of the continental « Moho » where it abuts against the top of the subducting PSP benath the SRA and the subvertical boundary between EP and PSP beneath E-Taiwan (see the black dashed line on Fig.7). It was often difficult to trace the « Moho » of the subducting PSP beneath those of the EP in the region of the SRA based on our 3D model because we lost resolution at such depths and because eclogitisation occurred in the slab. Focussing on the area offshore where we have improved the resolution compared with earlier models (see the thin line delimiting the region where significant rays cross, i.e., $>50$ rays/cell), we are able to confirm some previous observations and point new ones : 
(1) The thickness of the Huatung Basin crust averages 9-10 km before its subduction but it locally thickens up to $16 \mathrm{~km}$ beneath the Ryukyu forearc area as already noted by McIntosh and Nakamura (1998) based on wide-angle seismics.

(2) The crustal root of the LVA (purple crosses on Fig.7) can be traced at a mean depth of $32 \pm 3 \mathrm{~km}$ up to $24^{\circ} \mathrm{N}$ and it suddenly deepens to $42 \pm 3 \mathrm{~km}$ north of Hualien up to $24^{\circ} 20^{\prime} \mathrm{N}$.

(3) The PSP Moho deepens both northward and westward with a highest slope angle to the west down to a maximum depth of $65 \mathrm{~km}$ between 24 and $24^{\circ} 30^{\prime} \mathrm{N}$.

(4) The LVA is separated from the Central Range by a narrow elongated area of high velocities (see small red dots on Fig.7), typically 6-7 km/s rising close to the surface (15$20 \mathrm{~km}$ depth in general but locally up to $10 \mathrm{~km}$ immediately north of Hualien). Similar feature has been observed by Kuo-Chen et al. (2012). Such narrow high $\mathrm{V}_{\mathrm{p}}$ regions (HVZ) have also been mapped in the SRA as far east as $122^{\circ} 40^{\prime} \mathrm{E}$ beneath the southern slope of the SRA (Fig.7).

(5) The PSP Moho appears slightly undulating west of $122^{\circ} 50^{\prime} \mathrm{E}$ beneath the Ryukyu forearc (right below our seismic network). At a large scale, the strike of the isodepths changes from E-W (trench-parallel) east of $122^{\circ} 50^{\prime} \mathrm{E}$ to NW-SE $\left(\approx \mathrm{N} 305^{\circ}\right)$ west of it and then NNESSW $\left(\approx N 15^{\circ}\right)$ beneath the east coast of Taiwan. The PSP Moho is almost flat and shallow beneath the westernmost accretionary wedge near Taiwan and it is vertically offset downward by several kilometers near $24^{\circ} 15^{\prime} \mathrm{N}$ along a WNW-ESE-trending « step ». Less pronounced vertical offsets are detected perpendicular to the previous one beneath the Hoping Rise and the Nanao Basin. Such PSP Moho rise trending parallel to the E-Taiwan coast was already observed by previous tomographic models (Wu et al., 2007a ; Ustaszewski et al., 2012) but with a lower resolution in the absence of OBS data. The highest amplitude of the rise is observed at the latitude of Hualien right below the Hoping Rise. The Hoping Rise in the SRA basement toe is thus associated with a rise in the PSP Moho.

(6) A wide zone located offshore East Taiwan between $23^{\circ} 20^{\prime} \mathrm{N}$ and $24^{\circ} 30^{\prime} \mathrm{N}$ is characterized by anomalously low velocities (LVZ) between 7.5 and $8 \mathrm{~km} / \mathrm{s}$ in the PSP mantle below the Moho (see dashed brown line on Fig.7).

(7) The EP « Moho » rapidly deepens beneath the Central Range down to a depth of 60-70 $\mathrm{km}$ where it can not be traced deeper. Our results confirm those of Kuo-Chen et al. (2012) and Ustaszewski et al. (2012) up to $24^{\circ} 30^{\prime} \mathrm{N}$, but differ northward of this latitude. We do not observe any sign of eastward subduction of the EP north of $24^{\circ} 30^{\prime} \mathrm{N}$ whereas Ustaszewski et al. extend the subduction zone at least up to $25^{\circ} \mathrm{N}$. They also propose that the continental Moho above the subducting PSP has been newly formed by delamination and westward rollback of the lower part of the EP (and SRA) « slab ». Our data show that the average depth of the SRA Moho is 30-35 km but it deepens from $35 \mathrm{~km}$, at about 40 $\mathrm{km}$ east of the northeast coast of Taiwan, to about $55 \mathrm{~km}$ beneath the Ilan Plain.

(8) Our seismic network allows us to add new constraints at the junction between NE Taiwan and the SRA. The crustal root outlined by the EP « Moho » appears quite thick right beneath the Ilan plain coastal area as observed by Lin et al. (2004). Both the EP and the PSP Mohos isocontours are torned by $\sim 90^{\circ}$ near $24^{\circ} 30^{\prime} \mathrm{N}$ indicating an abrupt change in the $\mathrm{N} 10^{\circ}$ global trend beneath east Taiwan.

(9) The thickened crust of the EP and SRA around $24^{\circ} 35^{\prime} \mathrm{N}-122^{\circ} 05^{\prime} \mathrm{E}$ appears to be sharply cut at the contact with the subducting PSP (SRA Moho isocontours normal to the continental Moho edge), giving the impression that part of the orogen has been removed.

\section{5- Structure and deformation of the PSP}

The PSP mostly deforms offshore NE Taiwan where our OBS network has been deployed as indicated by the high density of shallow earthquakes (Fig.4). We will further characterize the structure and the deformation of the PSP on the basis of local tomographic sections (Figs.8\&9), relocated hypocenters and available focal solutions for main events (Figs.4\&5). 
The Huatung Basin is an Early Cretaceous oceanic domain which carries the LVA on its western edge and is bounded by the Gagua Ridge on its eastern edge. The undulations observed on the PSP Moho (see Fig.7) are rather caused by a bending of the plate as a consequence of its incipient subduction beneath East Taiwan than a buckling at a larger scale. Indeed, (1) the maximum amplitude is observed about $30 \mathrm{~km}$ off the east coast of Taiwan, (2) the wavelength is of the order of $100 \mathrm{~km}$ whereas it should be closer than $500 \mathrm{~km}$ for a 110-140 Ma old lithosphere and (3) the Huatung crust is limited by the Gagua Ridge to the east. As said above, we observe a thicker oceanic crust than those estimated from a $2 \mathrm{D}$ recent wide-angle experiment : 5-6 km after Klingelhoefer et al. (2012) but $12 \mathrm{~km}$ after McIntosh et al. (2005) compared with more than $9 \mathrm{~km}$ based on a 3D tomographic model. The discrepancy can be partly explained by the lower resolution of our tomography compared with refraction. Local thickening of the oceanic crust can also be caused by intra-oceanic slivering of the PSP as suggested by focal mechanisms of some recent $M \geq 6$ events (see events 24/4/72, 23/12/78, 14/11/86, 29/7/96, 14/4/00, 9/6/03, 1/6/05, 6/9/07 in Figs.4, 8\&9). Such thrust mechanisms (see on the left side of Fig.4) were already described and attributed to « lateral compression » in the direction of oblique convergence by Kao et al. (1998). ESE-WNW shortening of the PSP is required as a consequence of its collision against the steeply east-dipping EP slab up to $24^{\circ} 30^{\prime} \mathrm{N}$ (see sections 1 and 2 on Fig.8). The anomalous low velocities (LVZ areas on Figs.8\&9) observed beneath the PSP crust can be attributed either to a hydrated mantle as proposed by Klingelhoefer et al. (2012) or to the presence of slices of oceanic crust (and uppermost mantle ?) at depth (see section 3 on Fig.8). Hydration of the oceanic mantle at those depths $(30-70 \mathrm{~km})$ can result from hydrothermal alteration from the seafloor through fault conduits or from below since this area is contiguous with the LVA above the EP descending slab. Along section 1 (Fig.8), most of the seismicity occurs at depths between 30 and $55 \mathrm{~km}$ at the tip of the westward incipient subduction of the PSP crust but also within the brittle part of the oceanic mantle which undergoes strong ESE-WNW compression. Sections 2 and 3 (Fig.8) image the subducting PSP buried beneath the SRA basement and accretionary wedge. Again, earthquakes cluster at the tip of the westward subducting PSP crust as well as within the PSP mantle.

\section{2- The LVA and the suture zone in E-Taiwan}

The LVA is identified on sections 1 and 2 (Fig.8) because of its associated low velocity root and because it is known to outcrop along and offshore the Coastal Range. The arc can be traced below the east coast of Taiwan north of Hualien up to $24^{\circ} 20^{\prime} \mathrm{N}$ (Fig.7, section 2 on Fig.8). The tricky point concerns the presence of a narrow high velocity zone (HVZ) that fringes the LVA on its west side and locates below the " suture » between EP and PSP (heavy black dashed line on section 2, Fig.8). The surface projection of this narrow strip of high velocities is shown on figure 7 (elongated rise seen on the $7.5 \mathrm{~km} / \mathrm{s}$ isocontour marked with red dots). This narrow strip appears indented by the LVA along section 2 with velocities as high as $6.5 \mathrm{~km} / \mathrm{s}$ at only $8 \mathrm{~km}$ depth below the coastline just north of Hualien. Given to the structural position of the HVZ adjacent to the LVA and the velocities between 6.5 and $7.5 \mathrm{~km} / \mathrm{s}$, we suggest that this HVZ may correspond to pieces of oceanic crust (and uppermost mantle ?) that initially belonged to the LVA forearc basement and which are squeezed between the deformed LVA and the Taiwan orogeny in agreement with Kuo-Chen et al. (2012). Patches of HVZ are also observed below the southern slope of the SRA (Fig.7, section 3 on Fig.8 and sections 4, 5, 7 on Fig.9). These occurrences might indicate that the arc-continent collision migrated through there, east of its present location and that remnants of Luzon forearc (and arc ?) pieces were accreted at the front of the SRA basement. Focal mechanisms in the vicinity of the LVA are generally thrusts compatible with E-W shortening, sometimes with a significant left-lateral strike-slip component along a steep $\mathrm{N} 15^{\circ}$-trending reverse fault (M7 1951 earthquake on section 2 for example).

\section{3- The subducted part of the PSP}


Another type of deformation is observed in the subducted part of the PSP when looking in the direction normal to the Ryukyu trench (Fig.9). One basic question is the nature of the two seismic clusters that lie below the southern slope of the SRA, i.e., the Suao cluster near Taiwan and the Hoping cluster further east (Fig.4, Font and Lallemand, 2009 ; Theunissen et al., 2012a). Indeed, many historical earthquakes, including the largest one in 1920 (M7.7, Theunissen et al., 2010), occur in this region. The major question concerned the depth constraints on these events but this question has been likely solved using the new data acquired during the RATS experiments that allow us to precisely map the subduction interface (Fig.10) and relocate past seismic events in the new 3D velocity model.

The map of the subduction interface (Fig.10) reveals several features. Firstly, small scale undulations especially close to Taiwan likely correspond to slivering of the oceanic crust (see Fig.8) compatible with compression in the EP-PSP convergence direction. Such ESE-WNW « lateral » compression, already described by Kao et al. (1998) is attested by many reverse focal mechanisms (see section 5.1). Secondly, the PSP slab does not subduct smoothly beneath the SRA but rather shows ramps as already observed by Theunissen et al. (2012a). The ramps along the plates interface result from the northeastward downfaulting of the slab along en-échelon steeply-dipping shear zones trending NW-SE (Figs.9\&10). A close-view of the $V_{P}$ model where the velocity contours clearly mark a step is shown on section 5 (Fig.9). Spike tests were successfully performed in that region in order to guarantee the reliability of the $\sim 10 \mathrm{~km}$ vertical offset. The Hoping seismic cluster is clearly associated with one of the ramps that accommodates the slab offset (see sections 5, 6 and 7 on Fig.9). Major events occur either within the subducting plate or along the subduction interface. Focal solutions of the largest events are very homogeneous in this cluster (Font and Lallemand, 2009 and see focal mechanisms on top of Fig.4 and on Fig.5) and the NW-SE trend of the shallow-dipping nodal planes argues for a thrust mechanism along the ramps which results from the downfaulted slab. According to the global geodynamic context, the motion along the subvertical shear zone cutting through the slab should be normal with a sinistral component. It has been suggested by some authors (Lallemand et al., 1997 ; Font et al., 1999; Theunissen et al., 2012a) that a tear develops within the PSP slab to account for the collision along the Coastal Range and the subduction north of it. The en-échelon ramps observed along the subduction interface and the change in slab dip across them argue for a growing tear, non-mature yet, with en échelon segments slightly oblique to the convergence direction. Normal fault mechanisms indicating NNE-SSW extension with sinistral component near the subduction interface or within the subducting PSP were calculated from events recorded during the 3-months RATS passive experiment (see events 7 and 13 in Theunissen et al., 2012a). On March 12, 1966, a M7.5 WNW-ESE pure sinistral strike-slip earthquake occured between $28 \mathrm{~km}$ (Engdhal et al., 1998) and $22 \mathrm{~km}$ depth (Kao et al., 1998), i.e., close to the subduction interface. The three M6 deeper ( 47 to $55 \mathrm{~km}$ ) aftershocks that occured in March and May 1966 with similar mechanisms were likely associated with this intra-slab sub-vertical shear zone. Accurate relocation of these events should be done to decipher whether they really occur within the subducting slab or not.

Another characteristics may reveal the age contrast between the oceanic crust on each side of the subducting PSP. The subducting crust of the Huatung Basin (HB) can be traced at least down to $\sim 50 \mathrm{~km}$ on sections 4 to 7 (Fig.9) whereas velocities up to $8 \mathrm{~km} / \mathrm{s}$ or more are observed in the crust deeper than $55 \mathrm{~km}$ beneath Yaeyama islands (Yonaguni, Iri-Omote, see Fig.10). We interpret these high velocities as the result of the eclogitisation process occurring shallower where the crust is younger. We also noted the presence of a small subducting ridge trending NW-SE right in the axis of the paleo-West Philippine Basin (WPB) spreading center reconstructed by Deschamps and Lallemand (2002). If the subducting elongated high corresponds to the paleo-WPB extinct ridge, then the age of the subducting WPB below the Yaeyama islands is about $35 \mathrm{Ma}$ to be compared with $140 \mathrm{Ma}$ on the west side of the subducting Gagua Ridge (Fig.10). We also pointed a systematic deepening of the subduction interface at depths larger than $30 \mathrm{~km}$ west of Yonaguni Island along the northern extent of Gagua Ridge. We 
propose that this deepening together with the trend change of the isocontours of the subduction

\section{6- Structure and deformation of the southern Ryukyu forearc}

To characterize the structure and the deformation of the SRA, we use two new MCS lines 12 and 22 acquired during the TAIGER project in addition to local tomographic sections, relocated earthquake hypocenters and available focal solutions for the main events.

\section{1- The SRA basement}

The mean thickness of the SRA crust is 30-35 km (Fig.7) which corresponds to the average depth of the EP continental « Moho » far from the arc-continent collision: 30-35 km as depicted by Nissen et al. (1995) in the northern margin of the South China Sea and 25-30 km in the Ryukyu Arc near Okinawa for example (Iwasaki et al., 1990 ; Kodaira et al., 1996). Furthermore, the thickest portion of the arc is clearly observed along its southern edge (south of Yonaguni Island or east of Suao, Fig.7) suggesting a truncation of a thick crust from the south extending at least as east as $123^{\circ} 30^{\prime} \mathrm{E}$. These observations lead to two conclusions: (1) the minimum thickness of the $\operatorname{arc}(25-30 \mathrm{~km})$ is representative of the rest of the Chinese platform, so that it precludes the arc from basal delamination processes as suggested by Ustaszewski et al. (2012) and (2) the thickest crust truncated along its southern edge might indicate that the Taiwan orogen extended there initially before its collapse and tectonic erosion associated with the ongoing subduction and/or Luzon forearc or arc material has been underplated. Based on the $7.75 \mathrm{~km} / \mathrm{s} \mathrm{V}_{\mathrm{p}}$ isovelocity, we observe the same thickness for the EP crust below the Ilan Plain (55 km) than Lin et al. (2004) but we are doubtful about its representativity as the EP Moho because Wang et al. (2010) based on receiver functions obtained a very thin crust right below the Ilan Plain $(18 \mathrm{~km}$ at station SLBB using only Moho $\mathrm{P}_{\mathrm{s}}$ arrivals). High $\mathrm{V}_{\mathrm{p}} / \mathrm{V}_{\mathrm{s}}$ ratio suggests partial melting at those depths (Lin et al., 2004) but at the same time, earthquakes occur in the same deep zone far above the PSP Benioff zone. We thus can not conclude about the real EP Moho depth in this area. Regarding the toe of the SRA basement, Font et al. (2001), based on a set of reflection seismic lines, have shown that promontaries (or uplifted regions) existed below the Hoping Rise and Nanao Rise (see Fig.1) and that the southern edge ends abruptly at the rear of the accretionary wedge. The new 3D tomography indicates that high velocity zones (HVZ near $6.5 \mathrm{~km} / \mathrm{s}$ ) are detected at shallow depths around $20 \mathrm{~km}$ within the SRA basement below the southern slope of the Ryukyu Arc (see Figs.7, 8 and 9). We correlate these shallow HVZ with those observed west of the LVA below the "suture » between the EP and the PSP. We propose that these HVZ might represent pieces of LVA forearc basement offscraped from the colliding PSP when the LVA crept along the southern Ryukyu margin around 1 or 2 m.y. ago.

The seismic image of the SRA basement is not clear as shown on the multichannel seismic line 12 acquired during the TAIGER-RATS project (Fig.11). Nevertheless, high-amplitude reflections marking the top of the basement can be followed southward beneath the sediment of the Nanao forearc basin. They stop right back of the crest made by the rear of the accretionary wedge (see arrow on Fig.11, km62). The refraction line acquired simultaneously also shows an abrupt termination of the SRA basement at the same location based on velocity contrast between the trench sediment accreted in the frontal wedge and the SRA basement (Klingelhoefer et al., 2012). Velocities inverted on section 6 (Fig.9) also point this abrupt change. Based on local tomography, the subduction interface on that section exhibits two ramps, one below the accretionary wedge where the reflections marking the top of the subducting oceanic crust disappear (see arrow on Fig.11, km70) and another below the slope break between the forearc basin and the SRA slope $(\sim \mathrm{km} 115$ on Fig.11). This last ramp is associated with the Hoping seismic cluster that mainly concentrates near the ramp but also extends above within the SRA basement. The distribution of relocated earthquakes in the vicinity of line 12 (same as those on section 6 of Figs.5\&9) shows two important things. First, the Hoping seismic cluster occurs in very narrow region that 
coincides with the main ramp of the subduction interface. Second, most of the events occur within the PSP crust or near the interface (see Fig.11) but still a significant number of them apparently occur within the upper plate. The small white dots are microevents recorded during the 3-months of passive recording using the OBS network, so that we are confident in their location. All are located at depths larger than $16 \mathrm{~km}$, i.e., close to the subduction interface, whereas the older events relocated using the new 3D velocity model but without OBS stations have a much larger extent in depth from the seafloor to about $32 \mathrm{~km}$. This vertical spreading may be caused either by the poor resolution in depth in the absence of near-field seismic network and some seismic/tectonic accommodation of the SRA basement above the ramp. We attribute the lost of deep reflections arcward of km62 (arrow on Fig.11) to strong internal deformation in this sector.

\section{2- Forearc vertical movements and extension}

A trench-sub-parallel line MCS-22 (see location on Fig.4 and section 3 of Fig.8) cuts through the forearc basins (Hoping, Nanao and East Nanao) and well illustrates the structural context of the SRA basement at the Hoping and Nanao rises (Fig.12). We see large variations in SRA basement depths along this line. If we take a reference line at the depth of the Nanao Basin deepest point, we can measure a vertical offset that exceeds $1 \mathrm{~km}$ for the Nanao Rise and $3 \mathrm{~km}$ for the Hoping Rise. The line MCS-22 is not ideally oriented parallel to the trench. It obliquely cuts the structures but still, we observe a large uplift of the SRA basement above the subducting northern extent of the Gagua Ridge accompanied by normal faulting as attested by the intense seismicity (see Nanao cluster on section 3 of Fig.8), numerous west-dipping normal faults visible on seismic lines (see Fig.12) and detailed bathymetric map (Lallemand et al., 1999). A recent expression of the E-W extension affecting the SRA basement is the occurrence of the December 18, 2001 M6.7 shallow earthquake that occurred within the Nanao Rise (Figs.4 and 8). The uplift of the Hoping Rise appears much larger allowing the SRA basement to outcrop on the seafloor with a scarp facing east (see Fig.12) and inducing a strong erosion of the folded Suao Basin strata. Our interpretation of section 3 (Fig.8) is that slices of the shortened Huatung Basin produce oceanic highs that deform the upper plate when subducting.

\section{3- Transcurrent faulting : dextral or sinistral ?}

The section 4 (Fig.9) cuts across the Suao cluster near Taiwan. There, the seismicity still occurs within the subducting slab but also extends throughout the upper plate from $35 \mathrm{~km}$ in depth up to the seafloor. The cloud of events outlines a south-dipping high-angle (probably) listric ESEWNW-striking fault. This is in agreement with focal mechanisms which are mostly strike-slip with nodal planes trending N-S (dextral motion) and E-W (sinistral motion). The aftershocks of major events like the " Nanao earthquake » (June 5, 1994, $\mathrm{M}_{\mathrm{s}} 6.1$ ) delineate a rupture along the E-W nodal plane (Wu et al., 1997 ; Kao et al., 1998). As said above, the relocated cluster is clearly elongated along an E-W direction from the surface down to $35 \mathrm{~km}$. We thus favor an E-W trending sinistral strike-slip mechanism for the «1994 Nanao earthquake » as well as for the June 14, 2001 M6.3 event reported on figure 6 and section 4 (Fig.9). We believe that the presence of this cluster right above the incipient tear within the PSP slab is not fortuitous. We thus propose that the motion along the incipient tear (presumably normal with a sinistral component) transfers a similar stress within the overriding plate that deforms accordingly (see the 1966 seismic crisis above). One may notice that such sinistral component along transcurrent faults is just the opposite that one may expect from strain partitioning within a forearc in a context of oblique convergence (McCaffrey, 1992 ; Chemenda et al., 2000). This observation leads us to suggest that strain partitioning localizing on these en-échelon shear zones is not caused by oblique subduction but rather by collision of the PSP with EP south of them and « free » subduction north of them. Such sinistral motion along faults either trench-parallel or convergence-parallel are likely caused by the present collision between the PSP and the EP south of $24^{\circ} 30^{\prime} \mathrm{N}$ as discussed by Lallemand et al. (1997). 


\section{7- Discussion and conclusions}

In this study, we have analysed a new set of data on the area offshore NE Taiwan including a new 3D velocity model, relocated earthquakes and two new seismic lines. Based on this detailed structural analysis, we can answer several questions regarding the geometry of the boundary between converging plates (EP, SRA and PSP), the deformation style in the area of plates interaction and finally the reason for the specific distribution of seismicity.

\section{1- Precise geometry of EP/PSP and SRA/PSP boundaries}

The three plates mainly interact offshore East Taiwan so that large uncertainties characterized earlier models before getting OBS constraints.

We propose a new map for the PSP subduction interface that accounts for the new dataset and that largely differs from previous ones mainly based on poorly constrained Benioff zone at shallow depths (e.g., Kao et al., 1998; Font et al., 1999; Wu et al., 2009a; Ustaszewski et al., 2012). Part of the discrepancy comes from the fact that the PSP is highly deformed west of $122^{\circ} 45^{\prime} \mathrm{E}$ in the prolongation of the western foot of the Gagua Ridge. We have shown that slicing and tearing of the oceanic crust accommodate a NW-SE shortening of the PSP. The cartoon on Fig.13 illustrates the tectonic forces acting in the EP-PSP system. Following Ustazewski et al. (2012), we consider that the sharp continental subduction of the EP beneath the Central Range of Taiwan acts as a vertical wall against which the PSP collides. This "wall", sketched with three thick arrows on Fig.13, is the present indenter of the PSP between Taitung and Nanao. It ends for us near $24^{\circ} 30^{\prime} \mathrm{N}$, so that north of this latitude, the deformed PSP is free to subduct in the northwest direction. NW-SE shortening together with incipient subduction of the PSP beneath the eastern coast of Taiwan is probably at the origin of the bulge visible on both the PSP Moho and top (Figs.7 \& 10) parallel to the east coast. Because of the obliquity between the LVA and the continent-ocean transition within the EP, collision started in the north and propagated toward the south (Fig.1; Suppe, 1984). We thus infer that the NW-SE compression and shortening increases from south to north. The combination of the contrast between shortening south of $24^{\circ} 30^{\prime} \mathrm{N}$ and "free" subduction north of this latitude with the strong slab pull expected from an old (and dense) oceanic plate favours the inception of a slab break off of the NW corner of the PSP. The present geometry indicates en-échelon ramps offsetting the plates interface that probably reveal sub-vertical shear zones that might evolve soon into a continuous tear. The seismic activity concentrates near these ramps.

Many authors have attempted to characterize the tectonic regime east of Taiwan (e.g., Wu et al., $2009 \mathrm{~b}$; Wu et al., 2010a\&b) but the poor vertical resolution of earthquakes hypocenters conjugated with uncertainties in the affinity of the concerned domains, weakened the previous conclusions. Understanding the complex tectonics in this region requires to precisely map the frontiers between each colliding plate and thus know which deformation style is attributed to which plate. We did that properly when mapping the interface between the SRA and the PSP but we still have uncertainties below the northeast coastal area between Hualien and Ilan as indicated in figure 10 and in a lesser extent in mapping the Mohos beneath Suao and Ilan (see Fig.7). Based on 10 years of onland seismic records, Lin et al. (2004) have identified a channellike body starting from a depth of $120 \mathrm{~km}$ north of Ilan and reaching about $20 \mathrm{~km}$ north of Hualien, i.e., along the supposed PSP slab edge. The material within that "channel" was characterized by low $V_{s}$ and high $V_{p} / V_{s}$ ratios that pushed the authors to interpret it as melting features caused by dehydration processes from the subducted plate. This narrow area, difficult to map, is deforming extremely rapidly (see the rapid changes in GPS motions within a small sector; e.g., Rau et al., 2008). It is also the locus of atypical magmatism such those of Turtle Island (R. Shinjo, pers. comm.). Our new 3D velocity model is not good enough at those great depths to resolve those questions. 
Each converging plate undergoes deformation that depends on its rheology and inherited structure.

Starting from the PSP, and especially the old Huatung Basin lithosphere which lies between the east coast of Taiwan and the Gagua Ridge, we observe a range of facts (earthquakes, crustal shape and thickness, kinematics) that argue in favour of its NW-SE shortening through folding and slicing. Both types of deformation occur essentially at the crustal level with the help of a weak (hydrated) upper lithospheric mantle. We have imaged a wide zone offshore NE Taiwan (see LVZ in Fig.7) with low velocity anomalies at depths far below the Moho of the PSP (Figs.8 \& 9) that we interpret as evidences for intra-oceanic thrusting. The largest intra-PSP earthquakes mostly occur along its western edge (Fig.4) where the LVA undergoes strong compression. The Taiwan orogen results primarily from the indentation of the EP by the LVA producing an accretionary wedge made of crustal slivers originating from the Chinese platform (e.g., Suppe, 1981). This process is still active in the southern part of the island but our observations show that, today, the EP indents the PSP in central Taiwan (Fig.13) as suggested by Wu et al. (1997). The next step is a flip of subduction polarity that is starting in the Hualien region (south of $24^{\circ} 20^{\prime} \mathrm{N}$ ) where incipient subduction of the PSP beneath the Central Range has been evidenced (Chemenda et al., 1997).

There has been a long debate on the fate of the LVA forearc basement since it is apparently absent all along the Coastal Range (e.g., Malavieille et al., 2002). Based on the root of the LVA which is reported in Fig.7, we observe that the axis of the LVA is offset in three en-échelon segments mostly offshore the east coast except near $23^{\circ} 25^{\prime} \mathrm{N}$ where the Chimei volcanic edifice outcrops onshore. The LVA is thus almost fully submerged offshore the east coast. It is possible to trace it below the steep submarine slope north of Hualien at larger depths since it is buried and underthrusted below the Central Range of Taiwan (Figs.7 and 8). The en-échelon pattern may be inherited from the original morphology of the volcanic edifices as it appears south of Taiwan (Fig.1) but also the result of progressive underthrusting of arc slivers as proposed by Malavieille et al. (2002). A singular feature has been evidenced from the new velocity model which is the presence of a narrow high velocity zone (HVZ) west of the LVA. The HVZ also trends en-échelon parallel to the LVA segments. The surface projection of the HVZ coincides with the northern part of the Coastal Range and Longitudinal Valley (we did not investigate the southern part because it is out of our resolved area) as well as the eastern part of the Central Range north of Hualien. We thus propose that the HVZ represent relics of the LVA forearc basement squeezed between the EP and the PSP.

We did not focussed much on the EP deformation since it has been extensively studied using landstations (Wu et al., 2007a, 2009a). The new insights provided by our dataset rather concerns the transition between the EP and the SRA and the characterization of the southern edge of the SRA in the studied area. We have seen that the thickness of the SRA near Yonaguni and Iri-Omote islands averages $32 \pm 4 \mathrm{~km}$, the thickest portion being truncated along the southern edge. We use the term "truncation" since generally, the island arcs are thicker below the islands than along the contact with the subducting plate. We also use the term "truncation" because the upper plate crust thickens when approaching Taiwan between $122^{\circ} 25^{\prime} \mathrm{E}$ and $121^{\circ} 55^{\prime} \mathrm{E}$ with isocontours normal to the continental Moho southern edge (Fig.7). This domain corresponds to the transition between the EP, considered as fixed in Fig.1, and the SRA moving south at rates 5 to $7 \mathrm{~cm} / \mathrm{yr}$. We did not find localized deformation areas such as $\mathrm{N}-\mathrm{S}$ trending shear zones that would accommodate the southward drifting of the SRA with respect to Eurasia. We thus conclude that the deformation is distributed over a wide zone between the east coast of Taiwan and Yonaguni Island. The only localized shear zone that we have evidenced trends ESEWNW offshore at the latitude of Nanao city (see Fig.1 and section 4 in Fig.9). It probably 
corresponds with a sinistral strike-slip fault compatible with several focal mechanisms of earthquakes in this region (Fig.4). It has been interpreted by Huang et al. (2012) as the result of the bending of the northern Central range in response to the SOT opening. We suggest that the interaction of the Central Range in depth by the LVA also contributes to this "extrusion tectonics". Trench-parallel sinistral motion along SRA faults has also been revealed by a M7.5 earthquake in 1966 (Fig.4). We consider that such transcurrent motion along faults, visible in the detailed bathymetry (Lallemand et al., 1999), might have also been triggered by the growing tear within the subducting PSP (see section 7.1). Since the aftershocks of the 1966 earthquake occurred within the subducting slab and delineated a WNW-ESE left-lateral shear zone, we conclude that there is a strong coupling between the plates in this region. The last point concerning the southern edge of the SRA basement is that HVZ have been found at shallow levels north of the Hoping and Nanao basins. The occurrence of these HVZ together with the "truncation" evidences of the southern edge of the SRA basement argue in favour of relics of the Luzon volcanic forearc (and arc ?) incorporated at the toe of the SRA. We suggest that the former northern passive margin of the SCS was strongly shortened/thickened and then eroded tectonically when the Ryukyu trench propagated westward during the last 5-8 m.y. (Lallemand et al., 2001) and that pieces of the LVA and forearc were accreted at the front of the truncated newly active margin. The baïonet shape of the SRA and forearc basins (Fig.1) is, at least partly, the result of uplift of the SRA basement (Hoping and Nanao rises; see Fig.12) in response to the shortening and thickening of the subducting PSP. Crustal accretion of the former LVA beneath the toe of the SRA basement might also have contributed in the observed uplifted zone.

\section{3- Seismicity clustering and maximum potential earthquake magnitude}

One major question concerns the possible occurrence of great earthquakes $(M>8.5)$ in this region characterized by a high seismic rate. We already know that the largest instrumentally recorded earthquake in this region (including Taiwan) reached a moment magnitude 7.7 (Theunissen et al., 2010). This event in 1920 occurred at the junction between the Suao and Hoping clusters (Fig.4). Two other large subduction earthquakes occurred since 1920 with a $\sim 40$ yrs recurrence interval in the same area (Fig.4) : the $1963 \mathrm{M}_{\mathrm{w}} 7.2$ and $2002 \mathrm{M}_{\mathrm{w}} 7.1$ events. Based on our study, we interpret the concentration of the seismicity within both clusters as the result of the down-faulting of the PSP that creates ramps triggering the nucleation of earthquakes along the subduction interface. The upper plate deforms accordingly to accommodate the step-geometry of the subducting plate producing a seismic deformation right above the ramps. Most of the seismic energy thus appear to dissipate along several crustal (or lithospheric) faults cutting through the PSP (Fig.13) and the SRA (Fig.9). Based on interseismic GPS data along the Coastal Range, Hsu et al. (2012) suggest that the aseismic shallow southernmost Ryukyu subduction interface is fully locked. Considering a slip deficit accumulated over 500 years, they predict a potential earthquake magnitude up to 8.7 if the rupture goes from the east coast of Taiwan to the Gagua Ridge. To reach those conclusions, they made the hypothesis that the accumulated strain on the east coast was fully accounted by fault coupling along a unique surprisingly shallow (between 6 and $20 \mathrm{~km}$, see section 2.2) megathrust. Our results clearly indicate that a large part of the slip deficit is absorbed along intra-oceanic thrusts. Furthermore, the shallow subduction interface is segmented into surfaces with trench-parallel lengths smaller than $120 \mathrm{~km}$ (distance between east coast and Gagua), typically $60 \mathrm{~km}$ or less. The GPS approach is limited by the constraints of using onland stations (same limitation for the seismic approach before using OBS). To test the geodetic solutions would require the deployment of seafloor crustal deformation observatories (Ando et al., 2009). To conclude, the complex geometry of the subduction interface west of $123^{\circ} \mathrm{E}$ (northern prolongation of the Gagua Ridge) does not militate in favour of large ruptures, confirming the conclusions of Kao et al. (1998) and Theunissen et al. (2010). 
Fig.1 : Geodynamic context of Taiwan with orthogonal opposite subductions between the Philippine Sea Plate (PSP) and the Eurasia Plate (EP). East of Taiwan, the rift of the Southern Okinawa Trough (SOT) separates the main EP from the southward drifting South Ryukyu Arc (SRA). Arrows indicates the motion of some GPS stations with respect to the Penghu islands after Huang et al. (2010) for the eastern coast of Taiwan and Nakamura (2004) for the SRA. $V_{s}$ are subduction relative velocities between converging plates (EP/PSP or PSP/SRA). H.B. = Hoping Basin; H.R. = Hoping Rise; N.B. = Nanao Basin; N.R. = Nanao Rise; T.I. = Turtle Island; C.O.T. = continent-ocean transition; SCS $=$ South China Sea.

Fig. $2: 3 \mathrm{D}$ artist representation of the EP and SRA plates near Taiwan modified after Lallemand et al. (2001). Note the very steep subducting EP beneath central Taiwan partly explained by a tear propagating from north to south. Both cartoons are purely conceptual and the ideas behind are discussed in this paper.

Fig. 3 : 12 CNRS-INSU short period (SP) 4 components OBS (red dots) and 3 NTOU SP micrOBS (yellow dots) passive array deployed between July 19 and October 24, 2008 together with 7 US broadband (BB) OBS deployed during one year in the frame of the NSF TAIGER program (black dots). 24 micrOBS linear array deployed during the active experiment in May 2009, 19 SP micrOBS from IFREMER (white dots) and 5 from NTOU (blue dots).

Fig.4 : Relocated hypocenters of $5996 \mathrm{M}>3$ events recorded by the CWB and the JMA during the period 1992-2008 (east of $121^{\circ} \mathrm{E}$ ) using the new 3D local tomography (Theunissen et al., 2012a) and the new version of MAXI-code (Theunissen et al., 2012b). Three shallow seismic clusters mentionned in figures 8 and 9 are outlined : SC = Suao cluster, $\mathrm{HC}=$ Hoping cluster, $\mathrm{NC}=$ Nanao cluster. Multichannel seismic lines acquired during the active TAIGER-RATS experiments and shown on figures 11 and 12 are drawned : MCS-12 and MCS-22. A selection of major historical earthquakes is reported with their date of occurrence, revised moment magnitude (Theunissen et al., 2010) except for the 24/02/06 event (CWB solution) and focal mechanisms estimated from Harvard CMT in black, BATS in red and litterature in grey (Kao et al., 1998; Chen et al., 2004; Cheng et al., 1996; the focal mechanism of the 1920 earthquake does not exist, we only suggest that it was close to the Harvard CMT of an analog event : 9/10/1994 M ${ }_{\mathrm{w}}^{\prime} 4.9$ based on similar arrival times on common seismic stations, see Theunissen et al., 2010). This position is very close (< $10 \mathrm{~km}$ in horizontal and same depth) of the 31/3/2002 M7.1 thrust event. Hypocenters of earthquakes younger than 1991 were relocated but not those older than 1992 . Location of the tomography lines shown on figures 8 and 9. See Table 1 for earthquakes details.

Fig.5: Hypocenter comparison between CWB and our earthquakes relocation for all earthquakes having a well-determined focal mechanism along forearc sections 5, 6 and 7 (see location in Fig.4). In gray, the final selection of the 5996 relocated earthquakes. Yellow dots are relocated earthquakes having a focal mechanism. Blue squares are the same earthquakes located by CWB. Focal mechanism: black (GCMT), gray (Kao et al., 1998) and red (BATS, http://bats.earth.sinica.edu.tw/). The focal mechanism of the 1920 event with a question mark is based on the nearest earthquake having a focal mechanism compatible with the best candidate fault (see Theunissen et al., 2010). See Table 1 for earthquakes details.

Fig.6 : A: Seismic network used in this study including land and marine stations (in blue) as well as earthquakes recorded during the 3-months deployment (in red). The rays between earthquakes and stations indicate the spatial coverage of the passive experiment. B: 3D sketch of local P-waves tomographic sections with earthquakes (grey dots) and the area crossed by more than 50 rays per cell has been enlighted. 
Fig.7 : Isodepths of the EP Moho (in black) and PSP Moho (in white) mostly estimated from picking based on reference isocontours at $V_{p}=7.5 \mathrm{~km} / \mathrm{s}$ for the PSP and at $7.75 \mathrm{~km} / \mathrm{s}$ for the EP and SRA into the new 3D $V_{p}$ model. Seriated vertical sections within the $3 \mathrm{D} \mathrm{V}_{\mathrm{p}}$ model have been used to discriminate between both plates in the area of plates interaction. The black dashed line represents the southernmost extent of the continental Moho beneath the SRA as well as the subvertical boundary between EP and PSP beneath the Taiwan orogen. Black crosses mark the axis of the LVA, whereas small red dots delineate the regions of « high $\mathrm{V}_{\mathrm{p}}$ rise » that may reflect the suture in the collision zone. H.B. = Hoping Basin, H.R. = Hoping Rise, N.B. = Nanao Basin, N.R. = Nanao Rise, E.N.B. = East Nanao Basin.

Fig.8 : Three sections within the new 3D tomography model in the azimuth of the convergence between EP and PSP (see Fig.4 for location). The enlighted areas correspond to the inverted volume based on a minimum of 50 rays crossing the cells, whereas the pale regions almost correspond to the initial model (see the text for further details). EP = Eurasia Plate, PSP = Philippine Sea Plate, SRA = South Ryukyu Arc, LVA = Luzon Volcanic Arc, HVZ = High Velocity Zone, LVZ = Low Velocity Zone. The heavy dashed line in black represents the presumed boundary between EP and PSP. The areas outlined by a thin dotted line in yellow represents low velocity zones within the PSP mantle. Significant M $\geq 6$ earthquakes that occurred close to the sections are plotted with their focal mechanisms (vertical projection in the section's plane), their date of occurrence, their moment magnitude and their focal depth. The same events are plotted in map view on Fig.4. The section 3 is not far from the MCS line 22 shot during the US-Taiwan TAIGER survey in 2009. See Table 1 for earthquakes details.

Fig.9 : Four sections within the new 3D tomography model normal to the Ryukyu Trench. Same legend as figure 8. Focal solutions in forearc sections 5, 6 and 7 appear in figure 5. The inset within the section 5 represents the velocity model without interpretation in oredr to outline the subvertical offset within the subducting plate. The section 6 coincides with the wide-angle refraction ACTS line and the MCS line 12 shot during the US-Taiwan TAIGER survey in 2009.

Fig.10 : Isodepths of the top of the PSP. More than 50 seriated vertical sections within the 3D $V_{p}$ model have been used to constrain the subduction interface north of the Ryukyu Trench. The blue line outline the Ryukyu Trench and the Longitudinal Valley that marks the limit between EP and PSP onland. The faults in red were interpreted based on the seriated sections except the dextral strike-slip in the Huatung Basin which comes from Schnürle et al. (1998). The paleoWPB ridge axis is extrapolated from magnetic lineations south of the trench based on Deschamps and Lallemand (2002). As for the PSP Moho map on Fig.7, the change in trend of the isocontours west of Yonaguni Island might represent the limit between the WPB and the older Huatung Basin.

Fig.11 : Migrated depth section of multichannel seismic line 12 acquired during the TAIGERACTS project. See location on figure 4. The relocated earthquakes and the interpretation of the faulted subduction interface have been reported from section 6 of Fig. 9 for comparison with the velocity model. Grey dots : relocated 1992-2008 seismicity (see Fig.4). White dots : 2008 microevents recorded during the 3-months RATS experiment.

Fig.12 : Unmigrated TWT-time section of multichannel seismic line 22 acquired during the TAIGER project. See location on figure 4 and section 3 of figure 8 for comparison with the velocity model and seismicity distribution. Relocated earthquakes were not reported on this line because they would mask the normal faults affecting the Nanao Rise.

Fig.13 : Conceptual sketch illustrating the deformation of the PSP when it interacts with theTaiwan orogen. 
Fig.S1 : Depth difference between CWB locations and our earthquakes relocations. This map was built by using only the final selection of 5996 earthquakes for which a block median filter with an increment of $5 \mathrm{~km}$ has been applied to the depth difference. $\mathrm{SC}=$ Suao cluster, $\mathrm{HC}=$ Hoping cluster, $\mathrm{NC}=$ Nanao cluster.

Table 1 : List of parameters and source for focal mechanisms of earthquakes shown in figures 4, 5, 8 and 9. BATS means Broadband Array in Taiwan for Seismology, see Kao and Jian (2001) for more details. CMT means Global Centroid Moment Tensor (http://www.globalcmt.org/). The focal mechanism of the 1920 event is unknown but, based on Theunissen et al. (2010), the best candidate for this event is the seismogenic subudction interface. We thus suggest that the shallow-dipping thrust focal mechanism of the nearest earthquake after new 3D relocation, i.e., M7.1 31/03/02 event, is similar to those of the 1920 earthquake.

Acknowledgements. This paper reports the major results and interpretations obtained from the France-Taiwan RATS experiments conducted in parallel with the US-Taiwan TAIGER experiments offshore Taiwan from 2007 to 2009. This is a contribution to the French ANR ACTS Project in the frame of the France-Taiwan LIA ADEPT. We are grateful to ANR, NSC funding agencies, and the precious help of the BRT and BFT staffs as well as the captains, crews and scientific teams of the $R / V Y u$-Ying 2 and R/V Ocean Researcher 1. Anne Delplanque is warmly acknowledged for her excellent reworking on most figures and Stéphane Dominguez for his unique "french touch" in playing with 3D DEM files. Francis Wu, Hao Kuo-Chen, Wen-Tzong Liang, Stéphanie Gautier and Frauke Klingelhoefer have greatly facilitated the work during marine data acquisition and processing. They are also thanked for their constructive discussion. We also acknowledge some colleagues from the Géosciences Montpellier laboratory with whom we challenged our interpretations among with Jacques Malavieille, Stéphane Dominguez, Diane Arcay or Théo Berthet. This paper has been greatly improved thanks to Honn Kao and an anonymous reviewer. 


\section{References}

Ando, M., Nakamura, M., Matsumoto, T., Furukawa, M., Tadokoro, K., Furumoto, M., 2009. Is the Ryukyu subduction zone in Japan coupled or decoupled ? - The necessity of seafloor crustal deformation observation. Earth Planets Space 61, 1-9.

Angelier, J., Barrier, E., Chu, H.T., 1986. Plate collision and paleostress trajectories in a fold-thrust belt; the foothills of Taiwan. Tectonophysics 125(1-3), 161-178.

Angelier, J., Bergerat, F., Chu, H.T., Lee, T.Q., 1990. Tectonic analysis and the evolution of a curved collision belt; the Hsuehshan Range, northern Taiwan. Tectonophysics 183(1-4), 77-96.

Biq, C., 1972. Dual-trench structure in the Taiwan-Luzon region. Proceedings of the Geological Society of China 15, 65-75.

Carena, S., Suppe, J., Kao, H., 2002. Active detachment of Taiwan illuminated by small earthquakes and its control of first-order topography. Geology $30(10), 935-938$. doi:10.1130/0091-7613(2002)030<0935:ADOTIB>2.0.CO;2

Chai, B. H. T., 1972. Structure and tectonic evolution of Taiwan. Amer. J. Sci. 272(5), 389-422.

Chang, C. P., Angelier, J., Huang, C. Y., 2000. Origin and evolution of a melange: the active plate boundary and suture zone of the Longitudinal Valley, Taiwan. Tectonophysics 325(1-2), 43-62.

Chang, C.P., Chang, T.Y., Angelier, J., Kao, H., Lee, J.C., Yu, S.B., 2003. Strain and stress field in Taiwan oblique convergent system: Constraints from GPS observation and tectonic data. Earth Planet. Sci. Lett. 214, 115-127. doi:10.1016/S0012-821X(03)00360-1.

Chemenda, A. I., Yang, R. K., Hsieh, C. H., Groholsky A. L., 1997. Evolutionary model for the Taiwan collision based on physical modelling. Tectonophysics 274(1-3), 253-274.

Chemenda, A., Lallemand, S., Bokun, A., 2000. Strain partitioning and interplate friction in oblique subduction zones; constraints provided by experimental modeling. J. Geophys. Res. 105(B3), 5567-5581.

Chen, P.F., Ekstrom, G., Okal, A., 2004. Centroid moment tensor solutions for Taiwan earthquakes of the WWSSN era (1963-1975). Terr. Atm. Ocean. Sci. 15 (1), 61-73.

Cheng, S.N., Yeh, T.H., Yu, M.S., 1996. The 1951 Taitung earthquake in Taiwan. J. Geol. Soc. China 39 (3), 267-285.

Deschamps, A. E., Lallemand, S. E., Collot, J.-Y., 1998. A detailed study of the Gagua Ridge; a fracture zone uplifted during a plate reorganisation in the mid-Eocene. Mar. Geophys. Res. 20(5), 403-423.

Deschamps, A., Monie, P., Lallemand, S., Hsu, S. K., Yeh, K. Y., 2000. Evidence for Early Cretaceous oceanic crust trapped in the Philippine Sea Plate. Earth Planet. Sci. Lett. 179(3-4), 503516.

Deschamps, A., Lallemand, S., 2002. The West Philippine Basin; an Eocene to early Oligocene back arc basin opened between two opposed subduction zones. J. Geophys. Res. 107(B12), 24.10.1029/2001jb001706.

Dominguez, S., Lallemand, S. , Malavieille, J., Schnürle, P., 1998. Oblique subduction of the Gagua Ridge beneath the Ryukyu accretionary wedge system; insights from marine observations and sandbox experiments. Mar. Geophys. Res. 20(5), 383-402.

Engdahl, E.R., van der Hilst, R.D., Buland, R.P., 1998. Global teleseismic earthquake relocation with improved travel times and procedures for depth determination. Bull. Seismol. Soc. Amer. 88 (3), 722-743.

Fabbri, O., Fournier, M., 1999. Extension in the southern Ryukyu Arc (Japan); link with oblique subduction and back arc rifting. Tectonics 18(3), 486-497.

Faccenna, C., Di Giuseppe, E., Funiciello, F., Lallemand, S., van Hunen, J., 2009. Control of seafloor aging on the migration of the Izu-Bonin-Mariana trench. Earth Planet. Sci. Lett. 288(3-4), 386-398. doi 10.1016/J.Epsl.2009.09.042.

Font, Y., Lallemand, S., Angelier, J., 1999. Etude de la transition entre l'orogène actif de Taiwan et la subduction des Ryukyu; apport de la sismicité / Transition between the active orogen of Taiwan and the Ryukyu subduction; a new insight from seismicity. Bull. Soc. Geol. France 170(3), 271-283. 
Font, Y., Liu, C.-S., Schnurle, P., Lallemand, S., 2001. Constraints on backstop geometry of the Southwest Ryukyu subduction based on reflection seismic data. Tectonophysics 333(12), 135-158.

Font, Y., Kao, H., Lallemand, S., Liu, C.-S., Chiao, L.-Y., 2004. Hypocentre determination offshore of eastern Taiwan using the maximum intersection method. Geophys. J. Int. 158(2), 655675.

Font, Y., Lallemand, S., 2009. Subducting oceanic high causes compressional faulting in southernmost Ryukyu forearc a revealed by hypocentral determinations of earthquakes and reflection/refraction seismic data. Tectonophysics 466(3-4), 255-267.

Font, Y., M. Segovia, S., Vaca, Theunissen, T. 2013. Seismicity pattern along the Ecuadorian subduction zone: New constrains from earthquake location in a 3D a priori velocity model. Geophys. J. Int., doi: 10.1093/gji/ggs083.

Hall, R., Ali, J. R., Anderson, C. D., Baker, S. J., 1995. Origin and motion history of the Philippine Sea Plate. Tectonophysics 251(1-4), 229-250.

Heuret, A., Lallemand, S., Funiciello, F., Piromallo, C., Faccenna, C., 2011. Physical characteristics of subduction interface type seismogenic zones revisited. Geochem. Geophys. Geosyst. 12, Q01004, doi:10.1029/2010GC003230.

Ho, C. S., 1986. A synthesis of the geologic evolution of Taiwan. Mem. Geol. Soc. China 7, 15-29.

Hou, C.-S., Hu, J.-C., Ching, K.-E., Chen, Y.-G., Chen, C.-L., Cheng, L.-W., Tang, C.-L., Huang, S.-H., Lo, C.-H., 2009. The crustal deformation of the Ilan Plain acted as a westernmost extension of the Okinawa Trough. Tectonophysics 466(3-4), 344-355.

Hsu, S.-K., Sibuet, J.-C., 1995. Is Taiwan the result of arc-continent or arc-arc collision ? Earth Planet. Sci. Lett., 136, 315-324.

Hsu, Y. J., Yu, S. B., Simons, M., Kuo, L.-C., Chen, H. Y., 2009. Interseismic crustal deformation in the Taiwan Plate boundary zone revealed by GPS observations, seismicity, and earthquake focal mechanisms. Tectonophysics 479(1-2), 4-18.

Hsu, Y.J., Ando, M., Yu, S.B., Simons, M., 2012. The potential for a great earthquake along the southernmost Ryukyu subduction zone. Geophys. Res. Lett. 39 (L14302), doi:10.1029/2012GL052764.

Huang, C.Y., Shyu, C.T., Lin, S.B., Lee, T.Q.,, Sheu, D.D., 1992. Marine geology in the arc-continent collision zone off southeastern Taiwan: Implications for late Neogene evolution of the Coastla Range. Mar. Geol. 107, 183-212.

Huang, C.-Y., Yuan, P. B., Tsao S.-J., 2006. Temporal and spatial records of active arc-continent collision in Taiwan; a synthesis. Geol. Soc. Amer. Bull. 118(3-4), 274-288.

Huang, H. H., Shyu, J. B. H., Wu, Y. M., Chang, C. H., Chen, Y. G., 2012. Seismotectonics of northeastern Taiwan: Kinematics of the transition from waning collision to subduction and postcollisional extension. J. Geophys. Res. 117 (B01313). doi:10.1029/2011JB008852.

Huang, W. J., Johnson, K. M., Fukuda, J., Yu, S. B., 2010. Insights into active tectonics of eastern Taiwan from analyses of geodetic and geologic data. J. Geophys. Res. 115. doi $10.1029 / 2008 j \mathrm{jb006208.}$

Iwasaki, T., Hirata, N., Kanazawa, T., Melles, J., Suyehiro, K., Urabe, T., Moller, L., Makris, J., Shimamura, H., 1990. Crustal and Upper Mantle Structure in the Ryukyu Island-Arc Deduced from Deep Seismic-Sounding. Geophys. J. Int. 102(3), 631-651.

Kao, H., 1998. Can great earthquakes occur in the southernmost Ryukyu Arc-Taiwan region? Terr. Atm. Ocean. Sci. 9(3), 487-508.

Kao, H., Shen, S.-s. J., Ma, K.-F., 1998. Transition from oblique subduction to collision; earthquakes in the southernmost Ryukyu Arc-Taiwan region. J. Geophys. Res. 103(B4), 7211-7229.

Kao, H., Jian, P.-R., 2001. Seismogenic patterns in the Taiwan region : insights from source parameter inversion of BATS data. Tectonophysics, 333, 1-2, 179-198.

Kim, K.-H., Chiu, J.-M., Pujol, J., Chen, K.-C., Huang, B.-S., Yeh, Y.-H., Shen, P. 2005. Threedimensional $V_{p}$ and $V_{s}$ structural models associated with the active subduction and collision tectonics in the Taiwan region. Geophys. J. Int. 162(1), 204-220. 
1024

1025

1026

1027

1028

1029

1030

1031

1032

1033

1034

1035

1036

1037

1038

1039

1040

1041

1042

1043

1044

1045

1046

1047

1048

1049

1050

1051

1052

1053

1054

1055

1056

1057

1058

1059

1060

1061

1062

1063

1064

1065

1066

1067

1068

1069

1070

1071

1072

1073

1074

1075

1076

Kim, K. H., Chiu, J. M., Pujol, J., Chen, K. C., 2006. Polarity reversal of active plate boundary and elevated oceanic upper mantle beneath the collision suture in central eastern Taiwan. Bull. Seismol. Soc. Amer. 96(3), 796-806. 10.1785/0120050106.

Kimura, H., 1985. Back-arc rifting in the Okinawa Trough. Mar. Pet. Geol.(2), 222-240.

Klingelhoefer, F., Berthet, T., Lallemand, S., Schnürle, P., Lee, C.-S., Liu, C.-S., McIntosh, K., Theunissen, T., 2012. Velocity structure of the southern Ryukyu margin east of Taiwan : New results from ACTS wide-angle seismic experiment. Tectonophysics, doi:10.1016/j.tecto.2011.10.010

Kodaira, S., Iwasaki, T., Urabe, T., Kanazawa, T., Egloff, F., Makris, J., Shimamura, H., 1996. Crustal structure across the middle Ryukyu trench obtained from ocean bottom seismographic data. Tectonophysics 263(1-4), 39-60.

Konstantinou, K.I., Lee, S.-J., Font, Y., Kao, H., 2011. Rupture at the flank of the subducted Gagua ridge: The 18 December 2001 earthquake (Mw 6.8) offshore eastern Taiwan. Phys. Earth Planet. Int., doi:10.1016/j.pepi.2011.07.010

Kuo-Chen, H., Wu, F.T., Roecker, S.W., 2012. Three-dimensional P velocity structures of the lithosphere beneath Taiwan from the analysis of TAIGER and related seismic data sets. J. Geophys. Res. 117, B06306. doi:10.1029/2011JB009108.

Lallemand, S. E., Liu, C.-S., Font, Y., 1997. A tear fault boundary between the Taiwan Orogen and the Ryukyu subduction zone. Tectonophysics 274(1-3), 171-190.

Lallemand, S., Liu, C.-S., 1998. Geodynamic implications of present-day kinematics in the southern Ryukyus. J. Geol. Soc. China 41(4), 551-564.

Lallemand, S., Liu, C.-S., Dominguez, S., Schnürle, P., Malavieille, J., 1999. Trench-parallel stretching and folding of forearc basins and lateral migration of the accretionary wedge in the southern Ryukyus; a case of strain partition caused by oblique convergence. Tectonics 18(2), 231-247.

Lallemand, S. E., Font, Y., Bijwaard, H., Kao, H., 2001. New insights on 3-D plates interaction near Taiwan from tomography and tectonic implications. Tectonophysics 335(3-4), 229-253.

Letouzey, J., Kimura, M., 1986. The Okinawa Trough - Genesis of a Back-Arc Basin Developing Along a Continental-Margin. Tectonophysics 125(1-3), 209-230.

Lin, C.-H., 2000. Thermal modeling of continental subduction and exhumation constrained by heat flow and seismicity in Taiwan. Tectonophysics 324(3), 189-201.

Lin, J.-Y., Hsu, S.-K., Sibuet, J.-C., 2004. Melting features along the western Ryukyu slab edge (northeast Taiwan); Tomographic evidence. J. Geophys. Res. 109, B12402. doi:10.1029/2004JB003260.

Lin, J.-Y., Sibuet, J.-C., Hsu, S.-K., 2008. Variations of b-values at the western edge of the Ryukyu Subduction Zone, north-east Taiwan. Terra Nova, Vol 20, No. 2, 150-153.

Lin, K. C., Hu, J. C., Ching, K. E., Angelier, J., Rau, R. J., Yu, S. B., Tsai, C. H., Shin, T. C., Huang, M. H., 2010. GPS crustal deformation, strain rate, and seismic activity after the 1999 Chi-Chi earthquake in Taiwan. J. Geophys. Res. 115. doi 10.1029/2009jb006417.

Lu, C.-Y., Hsu K.-J., 1992. Tectonic evolution of the mountain belt. Petrol. Geol. Taiwan 27, 15-35.

Lu, C.Y., Malavieille, J., 1994. Oblique convergence, indentation and rotation tectonic in Taiwan mountain belt: Insights from experimental modeling. Earth Planet. Sci. Lett. 121, 477494.

Lu, C. Y., Angelier, J., Chu, H. T., Lee, J. C. (1995). Contractional, Transcurrent, Rotational and Extensional Tectonics - Examples from Northern Taiwan. Tectonophysics 246(1-3): 129146.

Malavieille, J., Lallemand, S. E., Dominguez, S., Deschamps, A., Lu, C.-Y., Liu, C.-S., Schnurle, P., Angelier, J., Collot, J. Y., and the ACT scientific crew, 2002. Arc-continent collision in Taiwan; new marine observations and tectonic evolution. Geol. Soc. Amer. Spec. paper $358,187-211$.

Malavieille, J., Trullenque, G., 2009. Consequences of continental subduction on fore-arc basin and accretionary wedge deformation in SE Taiwan; insights from analogue modeling. Tectonophysics 466(3-4), 377-394. 
McCaffrey, R., 1992. Oblique plate convergence, slip vectors, and forearc deformation. J. Geophys. Res. 97(B6), 8905-8915.

McIntosh, K., Nakamura, Y., 1998. Crustal structure beneath the Nanao forearc basin from TAICRUST MCS/OBS Line 14. Terr. Atm. Ocean. Sci. 9(3), 345-362.

McIntosh, K., Nakamura, Y., Wang, T. K., Shih, R. C., Chen, A., Liu, C. S., 2005. Crustal-scale seismic profiles across Taiwan and the western Philippine Sea. Tectonophysics 401(1-2): 23-54. 10.1016/j.tecto.2005.02.015.

Nakamura, M., 2004. Crustal deformation in the central and southern Ryukyu Arc estimated from GPS data. Earth Planet. Sci. Lett. 217(3-4), 389-398.

Nishimura, S., Hashimoto, M., Ando, M., 2004. A rigid block rotation model for the GPS derived velocity field along the Ryukyu Arc. Phys. Earth Planet. Int. 142(3-4), 185-203.

Nissen, S.S., Hayes, D.E., Buhl, P., Diebold, J., 1995. Deep penetration seismic soundings across the northern margin of the South China Sea. J. Geophys. Res. 100 (B11), 22407-22433.

Peacock, S. M., Hyndman, R. D., 1999. Hydrous minerals in the mantle wedge and the maximum depth of subduction thrust earthquakes. Geophys. Res. Lett. 26, $2517-2520$.

Rau, R.-J., Wu, F. T., 1995. Tomographic imaging of lithospheric structures under Taiwan. Earth Planet. Sci. Lett. 133(3-4), 517-532.

Rau, R.-J., Ching, K.-E., Hu, J.-C., Lee, J.-C., 2008. Crustal deformation and blocks kinematics in transition from collision to subduction: Global positionning system measurements in northern Taiwan, 1995-2005. J. Geophys. Res. 113(B09404). 10.1029/2007JB005414.

Schnürle, P., Liu, C.-S., Lallemand, S.-E., Reed, D., 1998. About a possible structural control of the Taitung Canyon east of Taiwan. Terr. Atmo. Ocean. Sci. 9 (3), 453-472.

Seno, T., Maruyama, S., 1984. Paleogeographic reconstruction and origin of the Philippine Sea. Tectonophysics 102(1-4), 53-84.

Seno, T., Stein, S., Gripp, A. E., 1993. A model for the motion of the Philippine Sea Plate consistent with NUVEL-1 and geological data. J. Geophys. Res. 98(B10), 17,941-17,948.

Sibuet, J.-C., Deffontaines, B., Hsu, S.-K., Thareau, N., Le Formal, J.-P., Liu, C.-S., and the ACT scientific party, 1998. Okinawa Trough backarc basin; early tectonic and magmatic evolution. J. Geophys. Res. 103(B12), 30,245-230,267.

Sibuet, J.-C., Hsu S.-K., 2004. How was Taiwan created ?. Tectonophysics 379(1-4), 159-181.

Simoes, M., Avouac, J. P., 2006. Investigating the kinematics of mountain building in Taiwan from the spatiotemporal evolution of the foreland basin and western foothills. J. Geophys. Res. 111(B10). doi 10.1029/2005jb004209.

Suppe, J., 1981. Mechanics of mountain building and metamorphism in Taiwan. Mem. Geol. Soc. China 4, 67-89.

Suppe, J., 1984. kinematics of arc-continent collision, flipping of subduction and back-arc spreading near Taiwan. Geol. Soc. China Mem. 6, 131-146.

Teng, L. S., 1990. Geotectonic evolution of late Cenozoic arc-continent collision in Taiwan. Tectonophysics 183(1-4), 57-76.

Teng, L. S., 1996. Extensional collapse of the northern Taiwan mountain belt. Geology 24(10), 949-952.

Teng, L. S., Lee, C. T., Tsai, Y. B., Hsiao, L.-Y., 2000. Slab breakoff as a mechanism for flipping of subduction polarity in Taiwan. Geology 28(2), 155-158. doi:10.1130/00917613(2000)28<155:SBAAMF>2.3.CO;2

Theunissen, T., Font, Y., Lallemand, S., Gautier, S., 2012b. Improvements of the Maximum Intersection Method for 3D absolute earthquake location. Bull. Seismol. Soc. Amer. 102-4. $10.1785 / 0120100311$.

Theunissen, T., Font, Y., Lallemand, S., Liang, W. T., 2010. The largest instrumentally recorded earthquake in Taiwan: revised location and magnitude, and tectonic significance of the 1920 event. Geophys. J. Int. 183(3), 1119-1133. doi 10.1111/J.1365-246x.2010.04813.X.

Theunissen, T., Lallemand, S., Font, Y., Gautier, S., Lee, C.-S., Liang, W.-T., Wu, F., Berthet, T., 2012a. Crustal deformation at the southernmost part of the Ryukyu subduction (East Taiwan) as revealed by new marine seismic experiments. Tectonophysics. 10.1016/j.tecto.2012.04.011 
Tsai, Y.-B., 1986. Seismotectonics of Taiwan. Mem. Geol. Soc. China 7, 353-367.

Ustaszewski, K., Wu, Y.-M., Suppe, J., Huang, H.-H., Chang, C. H., Carena, S., 2012. Crust-mantle boundaries in the Taiwan - Luzon arc-continent collision system determined from local earthquake tomography and 1D models: Implications for the mode of subduction polarity reversal. Tectonophysics TECTO 125328.10.1016/j.tecto.2011.12.029.

Wang, C., Chuang, S.-W., Li, M.-L., Cheng, W.-B., 2001. Lithospheric structure of Philippine Sea Plate near the western end of Ryukyu subduction zone and some of its tectonic effects. Terr. Atm. Ocean. Sci. 12(Suppl.): 287-304.

Wang, Z., Zhao, D., Wang, J., Kao, H., 2006. Tomographic evidence for the Eurasian lithosphere subducting beneath South Taiwan. Geophys. Res. Lett. 33, L18306. doi:10.1029/2006GL027166.

Wang, H.L., Zhu, L., Chen, H.W., 2010. Moho depth variation in Taiwan from teleseismic receiver functions. J. Asian Earth Sci. 37, 286-291. doi:10.1016/j.jseaes.2009.08.015.

Wu, F. T., 1970. Focal mechanisms and tectonics in the vicinity of Taiwan. Bull. Seismol. Soc. Amer. 60(6), 2045-2056.

Wu, F. T., 1978. Recent tectonics of Taiwan. J. Phys. Earth 26, S265-S299..

Wu, F. T., Rau, R.-J., Salzberg, D. , 1997. Taiwan Orogeny; thin-skinned or lithospheric collision?. Tectonophysics 274(1-3), 191-220.

Wu, Y.-M., Chang, C.-H., Zhao, L., Shyu, J. B. H., Chen, Y.-G., Sieh, K., Avouac, J.-P., 2007a. Seismic tomography of Taiwan; improved constraints from a dense network of strong motion stations. J. Geophys. Res. 112, B08312. doi:10.1029/2007JB004983.

Wu, F.T., Lavier, L., and the TAIGER team, 2007b. Collision tectonics of Taiwan and TAIGER experiments. EOS Trans., AGU, F. M. Suppl., San Francisco 88(52). Abstract T51A-0321.

Wu, Y.-M., Shyu, J. B. H., Chang, C.-H., Zhao, L., Nakamura, M., Hsu, S.-K., 2009a. Improved seismic tomography offshore northeastern Taiwan; implications for subduction and collision processes between Taiwan and the southernmost Ryukyu. Geophys. J. Int. 178(2), 10421054.

Wu, F. T., Liang, W.-T., Lee, J.-C., Benz, H., Villasenor, A., 2009b. A model for the termination of the Ryukyu subduction zone against Taiwan: A junction of collision, subduction/separation, and subduction boundaries. J. Geophys. Res. 114(B07404). doi:10.1029/2008JB005950.

Wu, W. N., Kao, H., Hsu, S. K., Lo, C. L., Chen, H. W., 2010a. Spatial variation of the crustal stress field along the Ryukyu-Taiwan-Luzon convergent boundary. J. Geophys. Res. 115. doi 10.1029/2009jb007080.

Wu, Y. M., Hsu, Y. J., Chang, C. H., Teng, L. S., Nakamura, M., 2010b. Temporal and spatial variation of stress field in Taiwan from 1991 to 2007: Insights from comprehensive first motion focal mechanism catalog. Earth Planet. Sci. Lett. 298(3-4), 306-316. doi 10.1016/J.Epsl.2010.07.047.

Yu, S.-B., Chen, H.-Y., Kuo, L.-C., 1997. Velocity field of GPS stations in the Taiwan area. Tectonophysics 274(1-3), 41-59. 
The procedure used to relocate the seismic events with MAXI-code is fully explained in Font et al. (2004) and Theunissen et al. (2012b). As said in the text, solutions are sorted according to confidence factors based on MAXI algorithm rather than rms error based. We chose equivalent criteria namely $\mathrm{Q}_{\mathrm{EDT}} \geq 0.6$ (ratio between 0 and 1 describing quality of Equal Differential Time volumes intersections); inter-barycenter distance (between volumes V1 and V3) $\leq 5 \mathrm{~km}$; V1 size $\leq 400 \mathrm{~km}^{3}$; and V2 size $\leq 200 \mathrm{~km}^{3}$. After selection, average rms was $0.20 \pm 0.03(1 \sigma)$ and average uncertainties $\left(X^{2}\right) \mathrm{dx}$, dy and $\mathrm{dz}$ were $0.94 \pm 0.51 \mathrm{~km}, 1.25 \pm 0.84 \mathrm{~km}$ and $2.25 \pm 1.69 \mathrm{~km}(1 \sigma)$ respectively. The final search volume, $\mathrm{V} 4$, may indicate also a kind of uncertainties: in particular V4 diameter spreads in depth from $5.1 \pm 2.7 \mathrm{~km}$ (up) to $5.4 \pm 2.7 \mathrm{~km}$ (down). In the final selection (5996 earthquakes), primary azimuthal gap ranges between $38^{\circ}$ and $315^{\circ}$, with an average value of about $133 \pm 29^{\circ}(1 \sigma)$. Distance to the first station is in average of $36 \pm 23 \mathrm{~km}$. There are $14 \pm 7 \%$ of outliers. Compared with the CWB catalog, relocations are distant (in 3D), on average, by 15.2 $\pm 14.6 \mathrm{~km}(1 \sigma)$ (median about $12 \mathrm{~km}$ ). Solutions are sorted according to confidence factors based on MAXI algorithm rather than rms error. We observe that our depths of relocation are, on average, $6.3 \pm 16.0 \mathrm{~km}(1 \sigma)$ (median of $4.4 \mathrm{~km}$ ) deeper than those of CWB. The median of depth difference between CWB hypocenters and our relocations is illustrated on figure S1. 


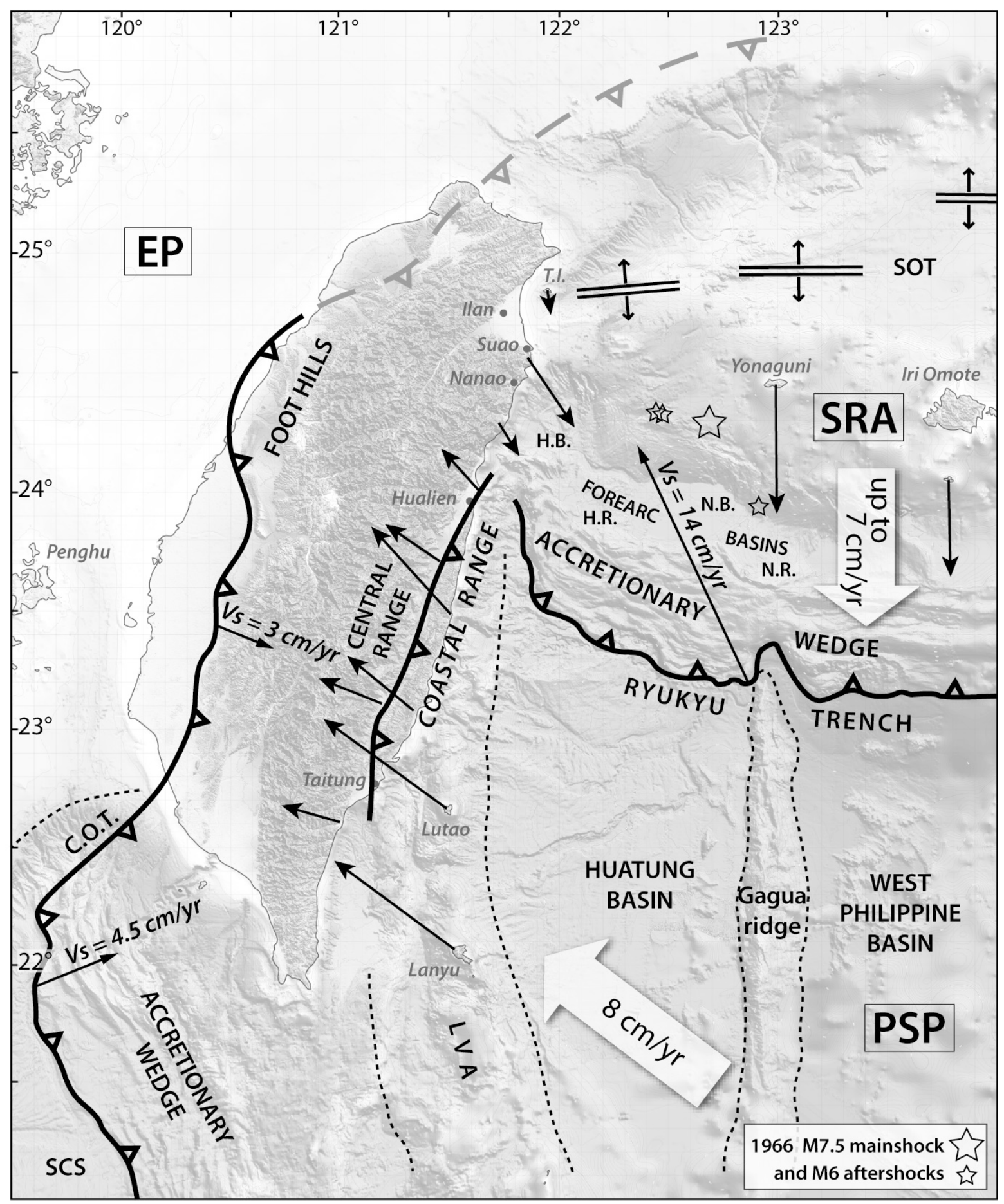




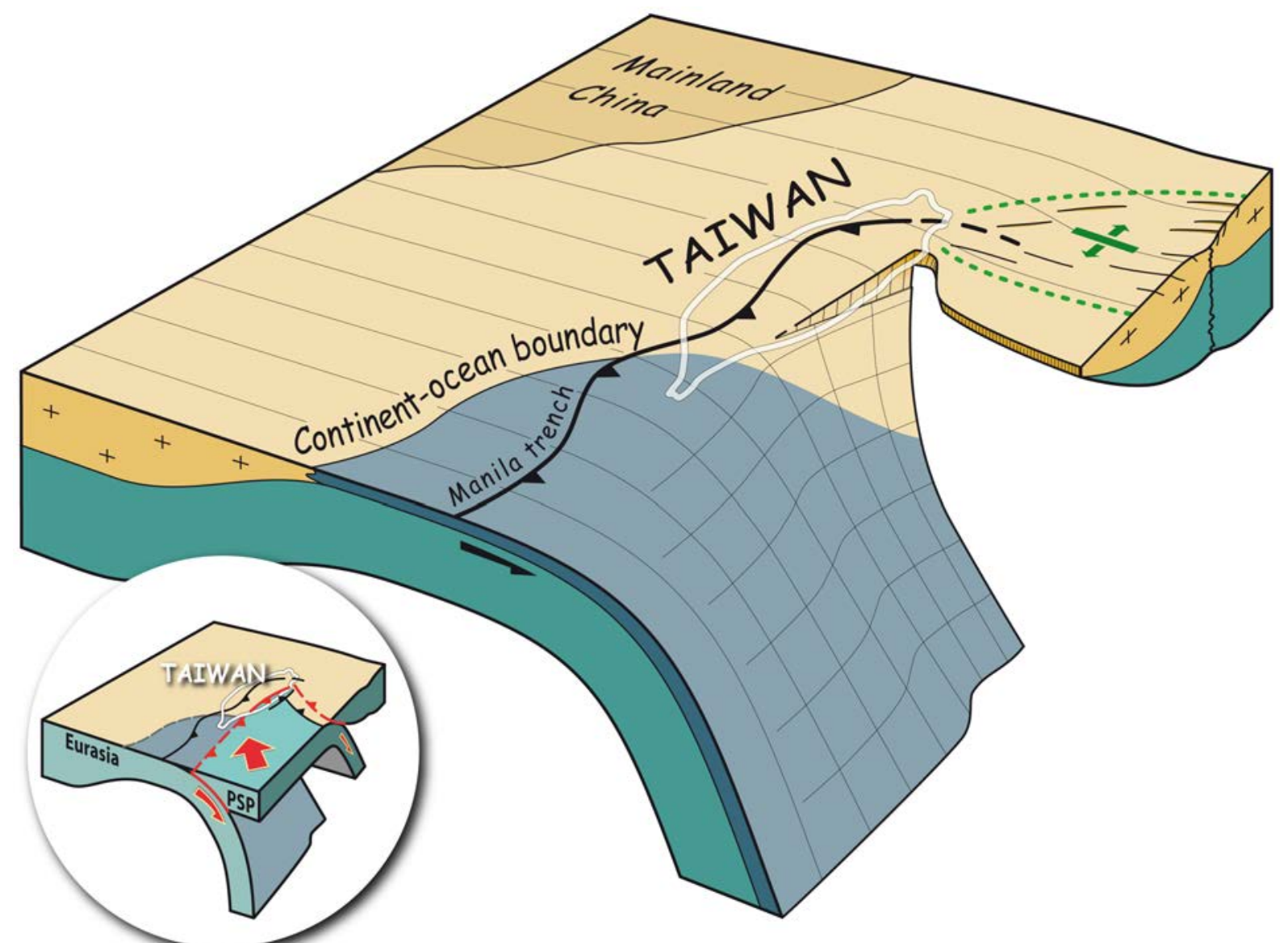

1195

Fig.2 


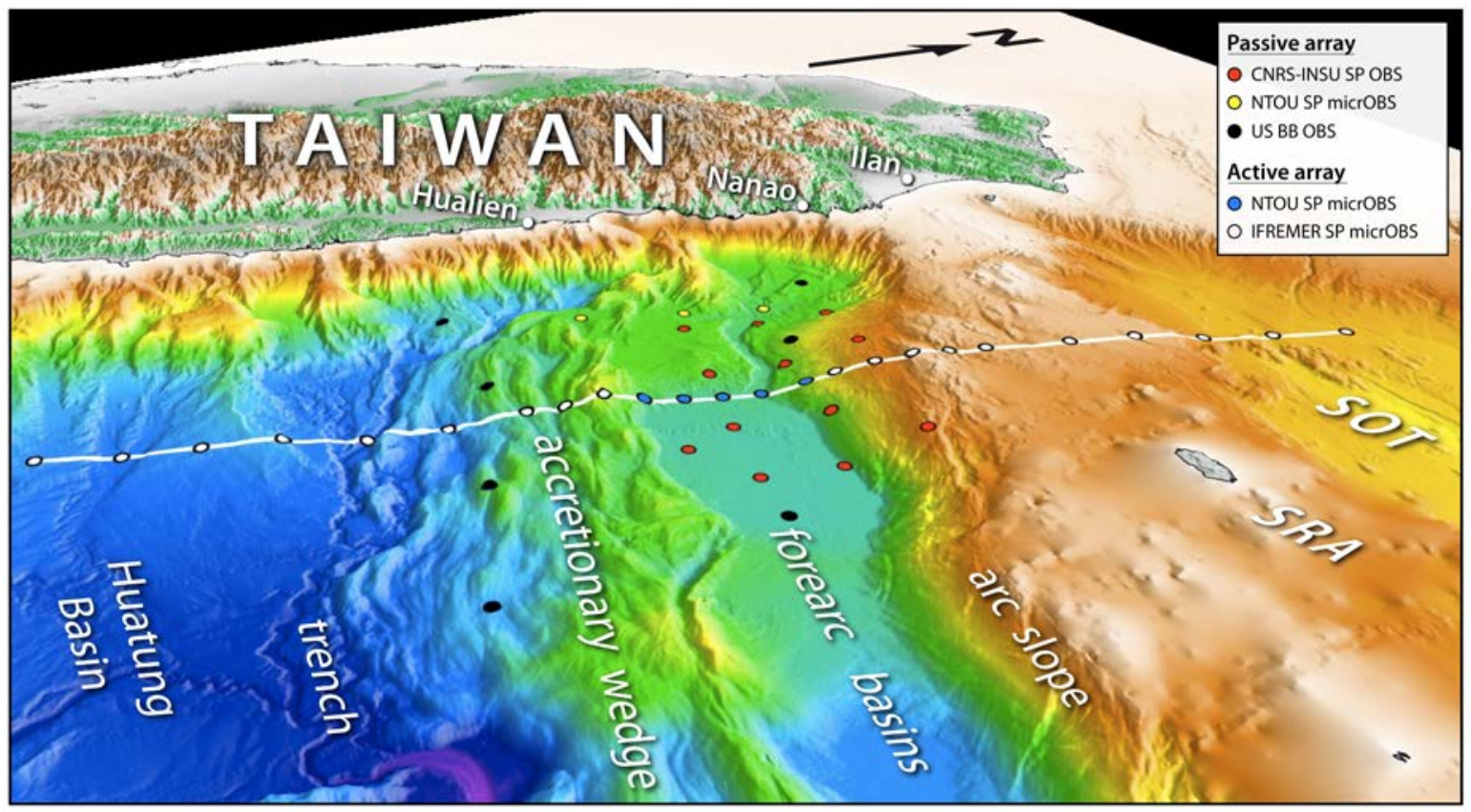

1198

Fig.3 


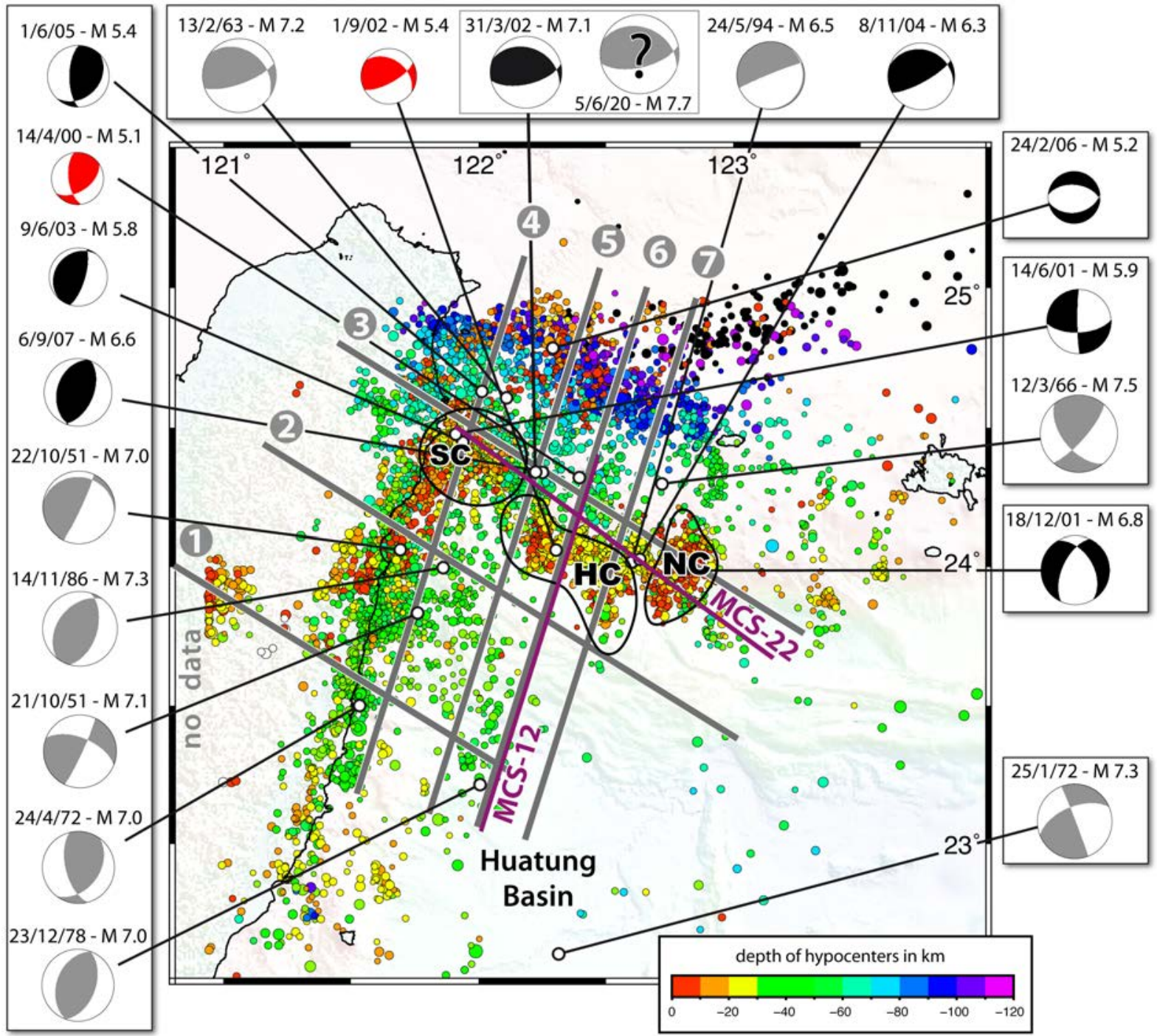

1200

Fig.4

1201 


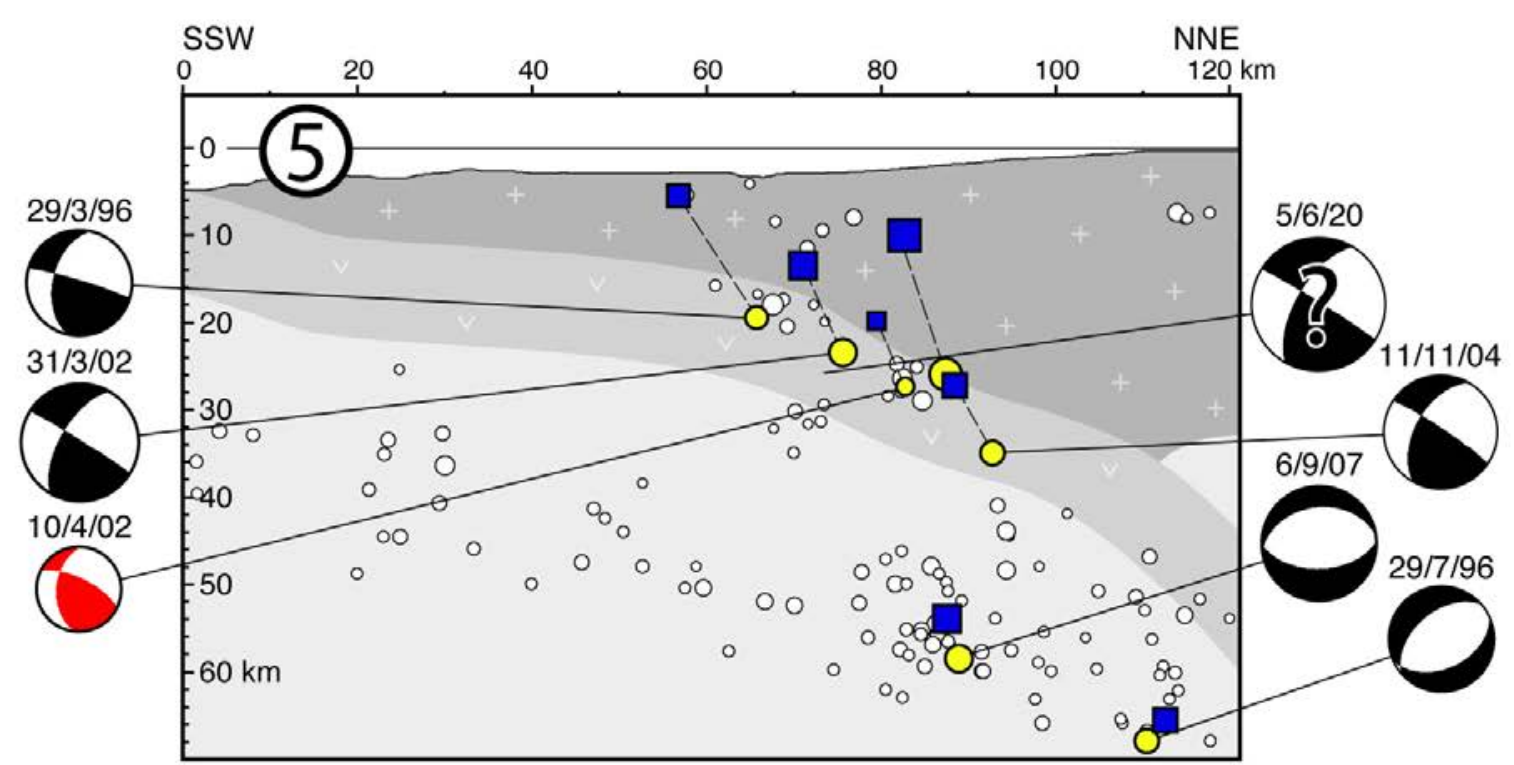

O new 3D location with focal mechanism $O$ new 3D location

CWB location of events with focal mechanisms

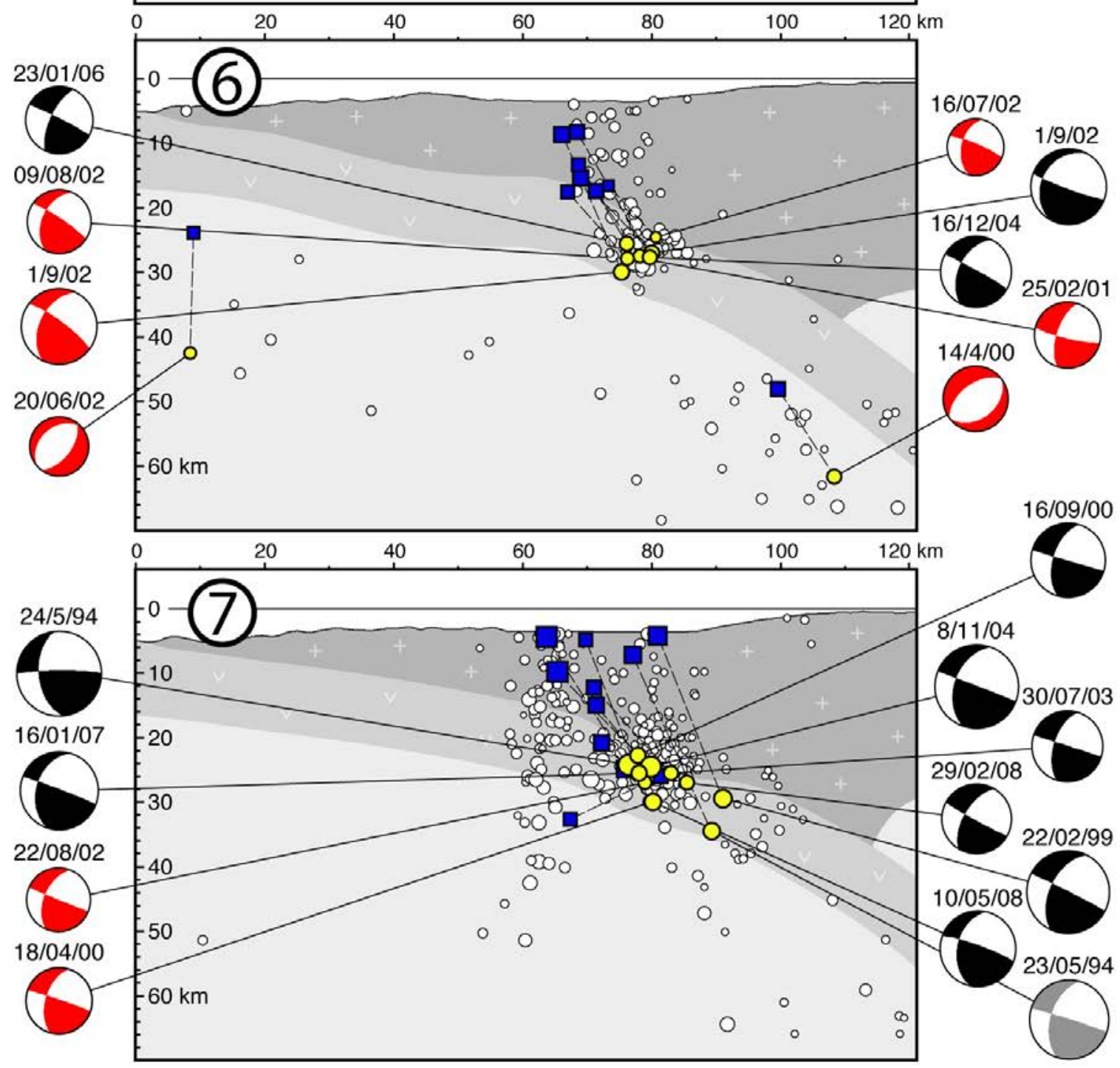

Fig.5 
(A)

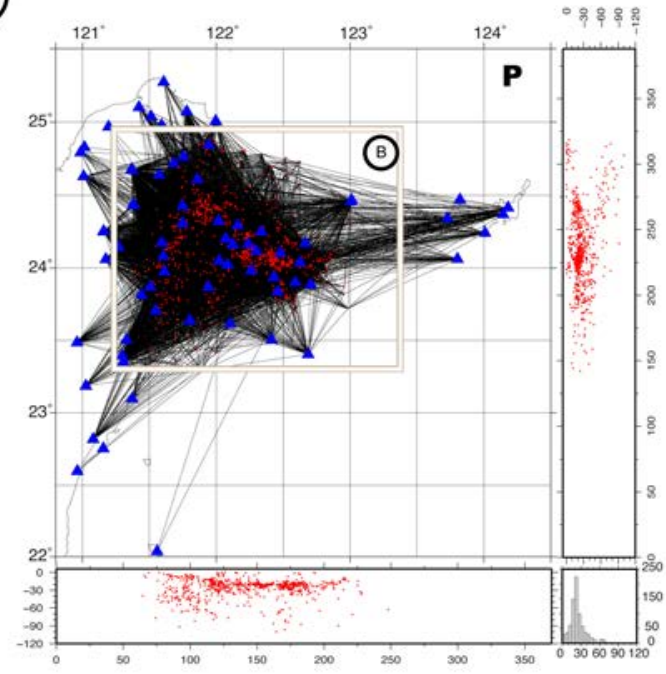

1205 1206

1207

\section{Fig.6}

(B)

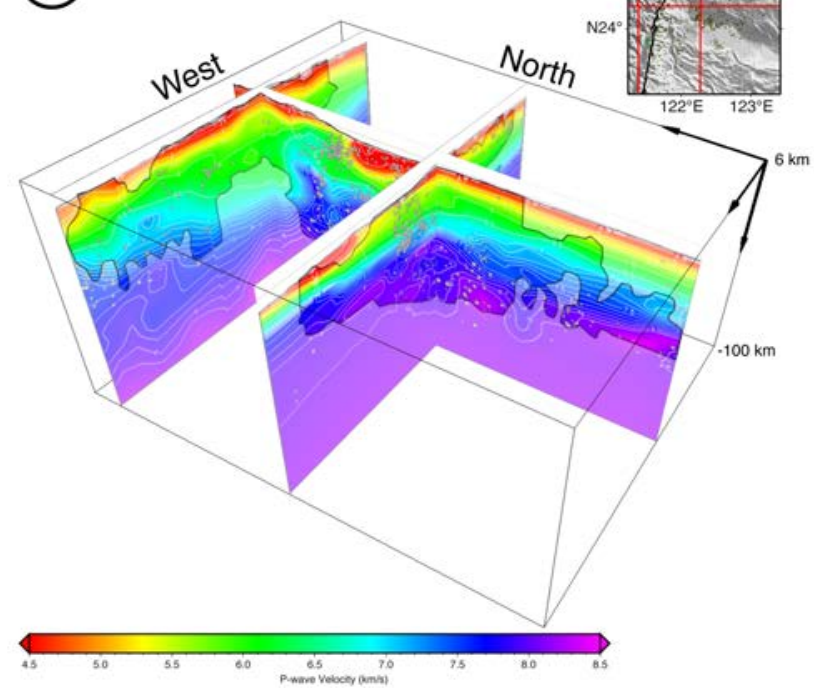




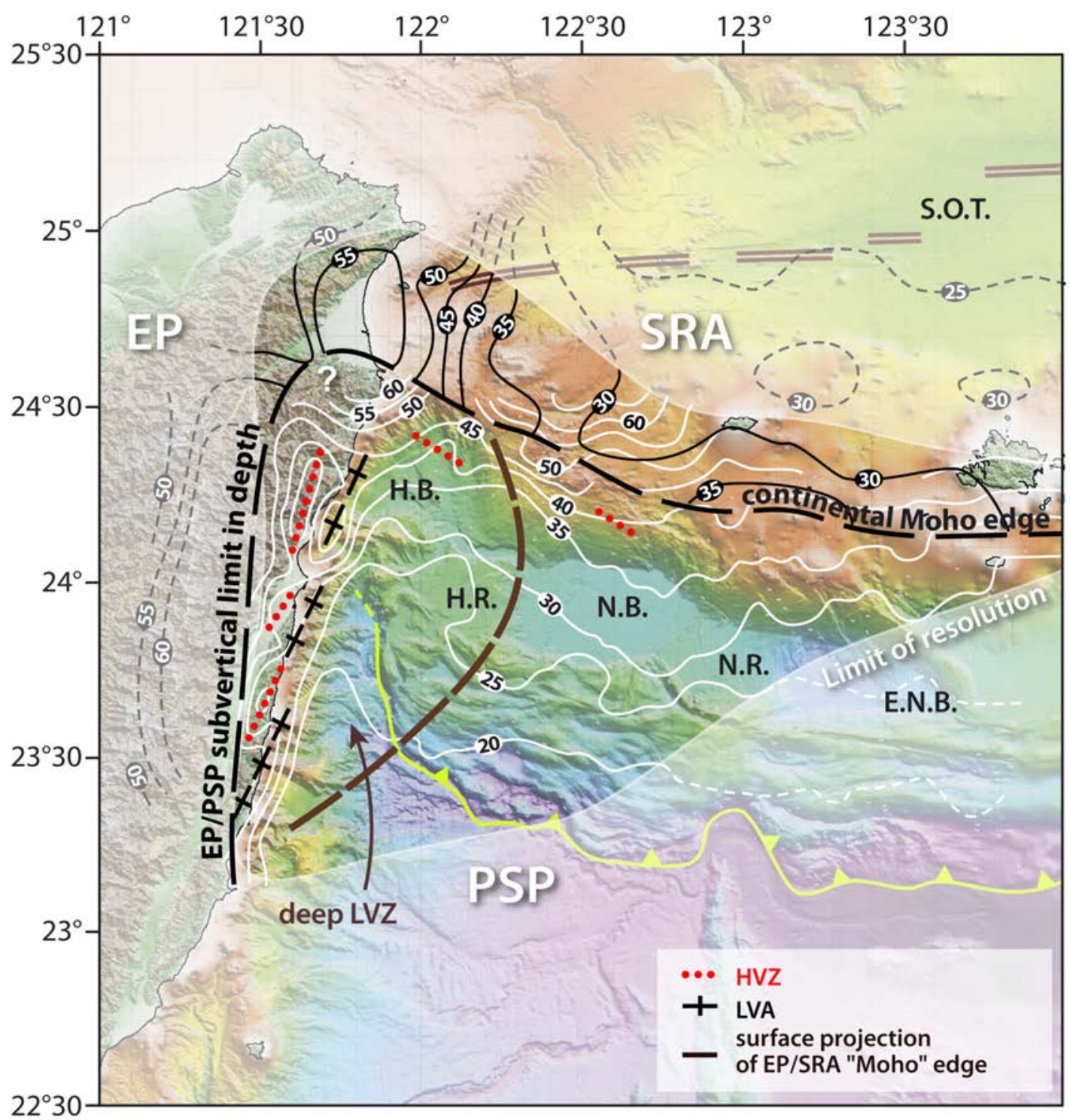

Fig.7 


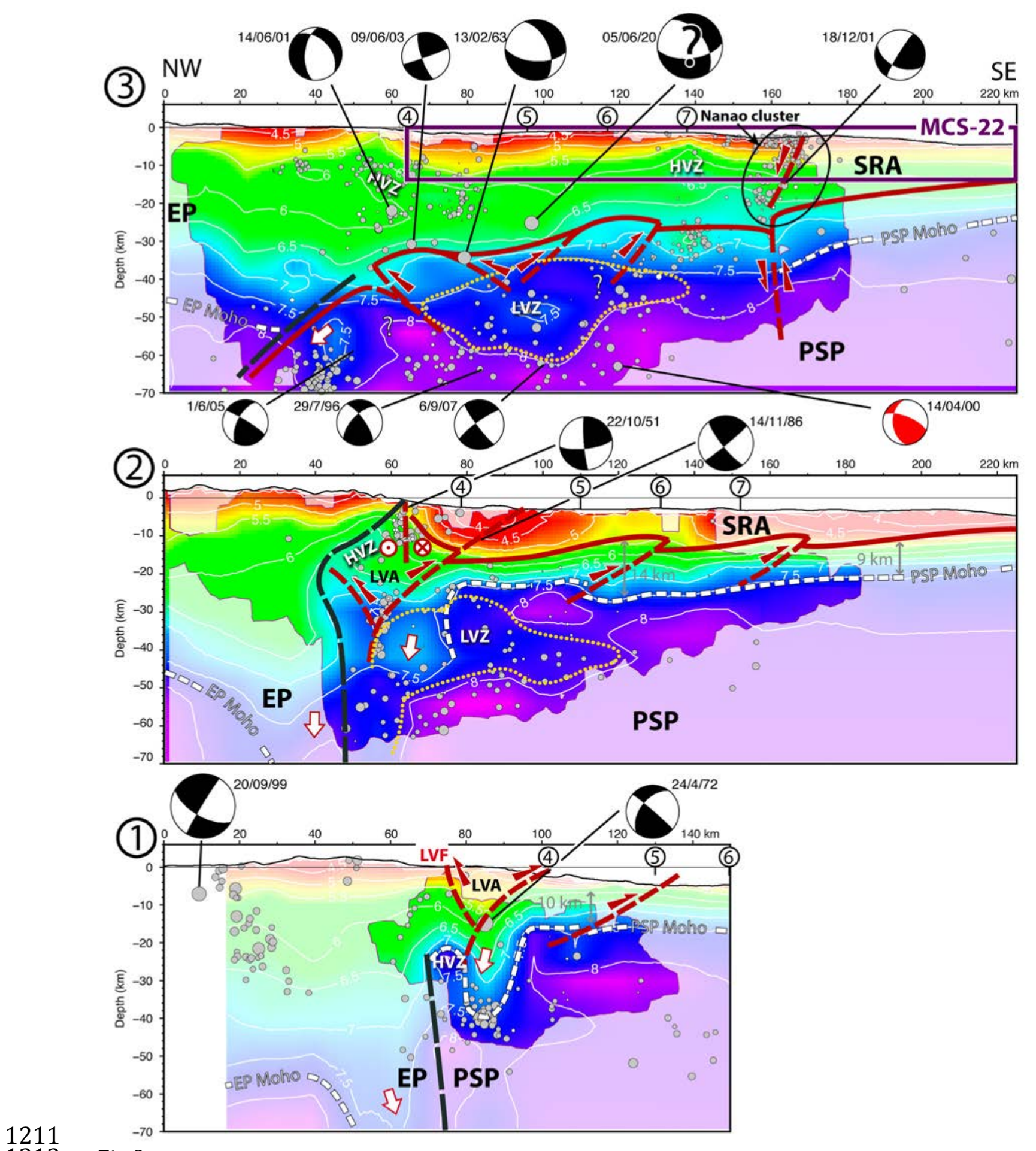

1211

1213

Fig.8 

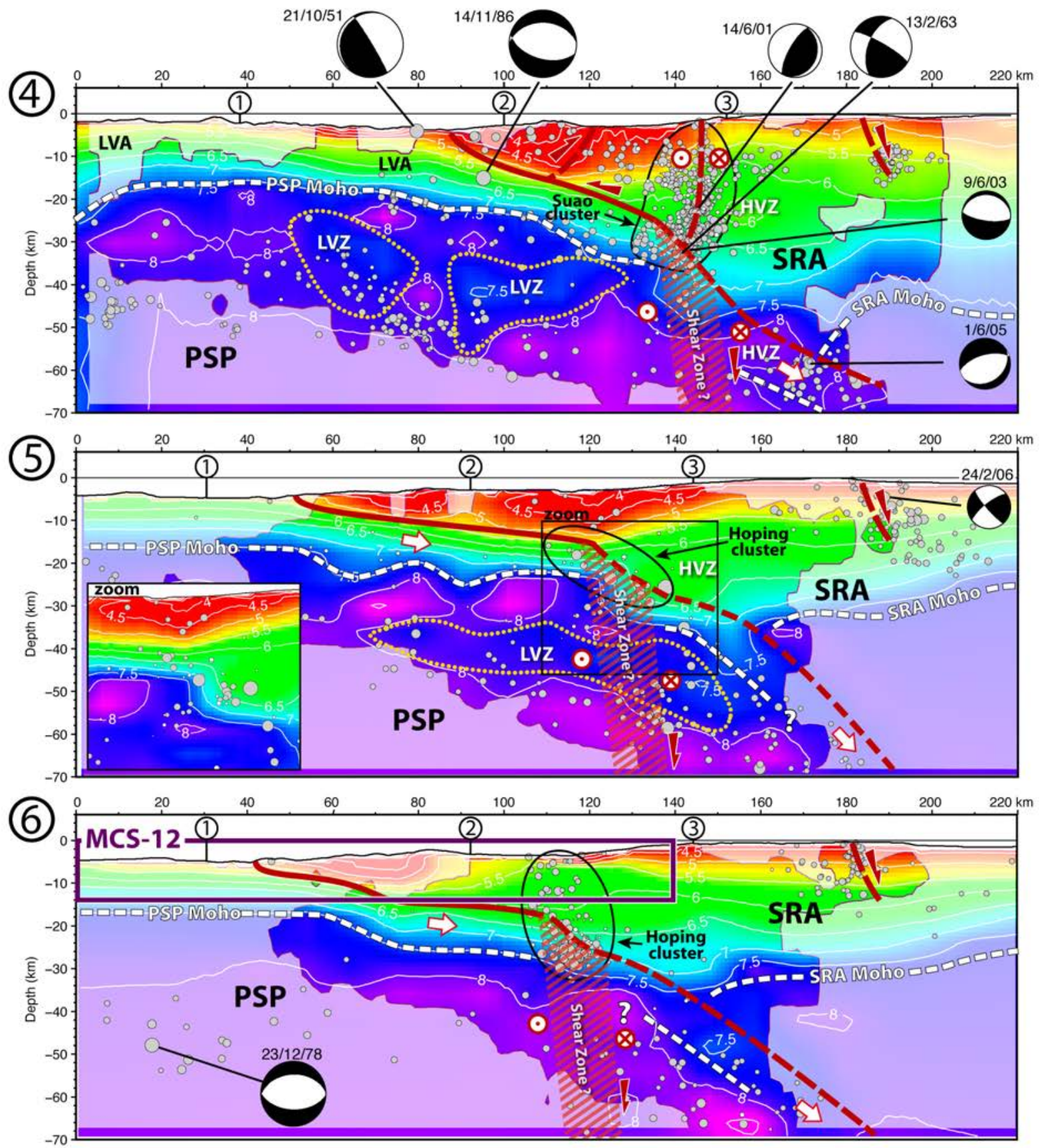

1214

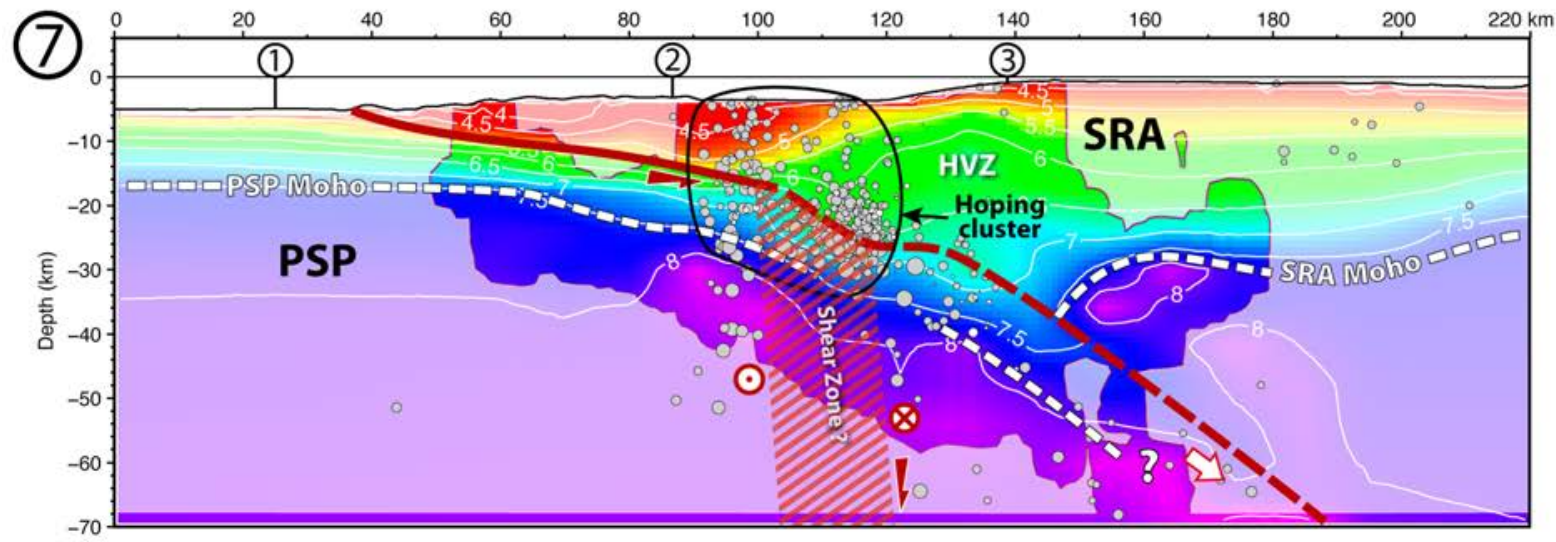

1215 Fig.9

1216 


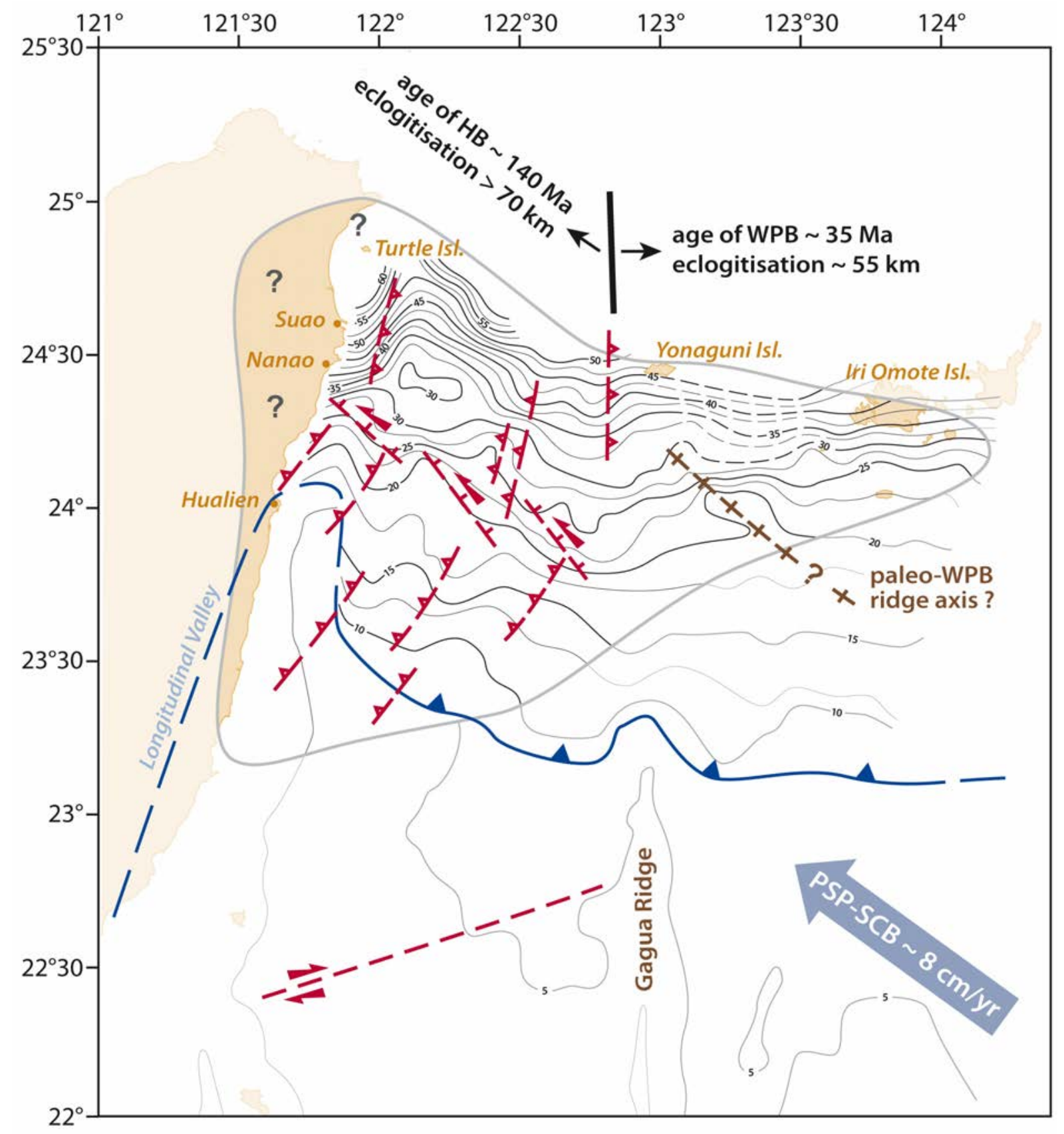

1217

1218

1219

Fig.10 


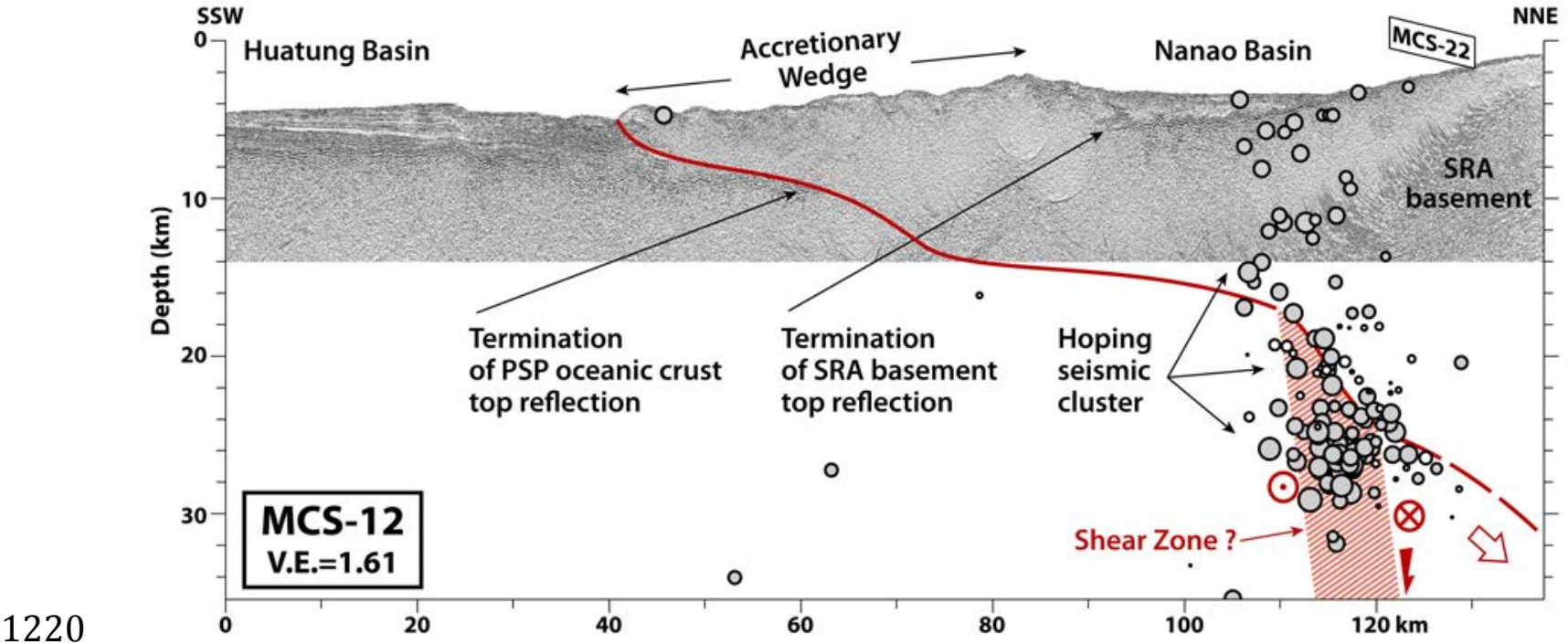

1221 Fig.11

1222 


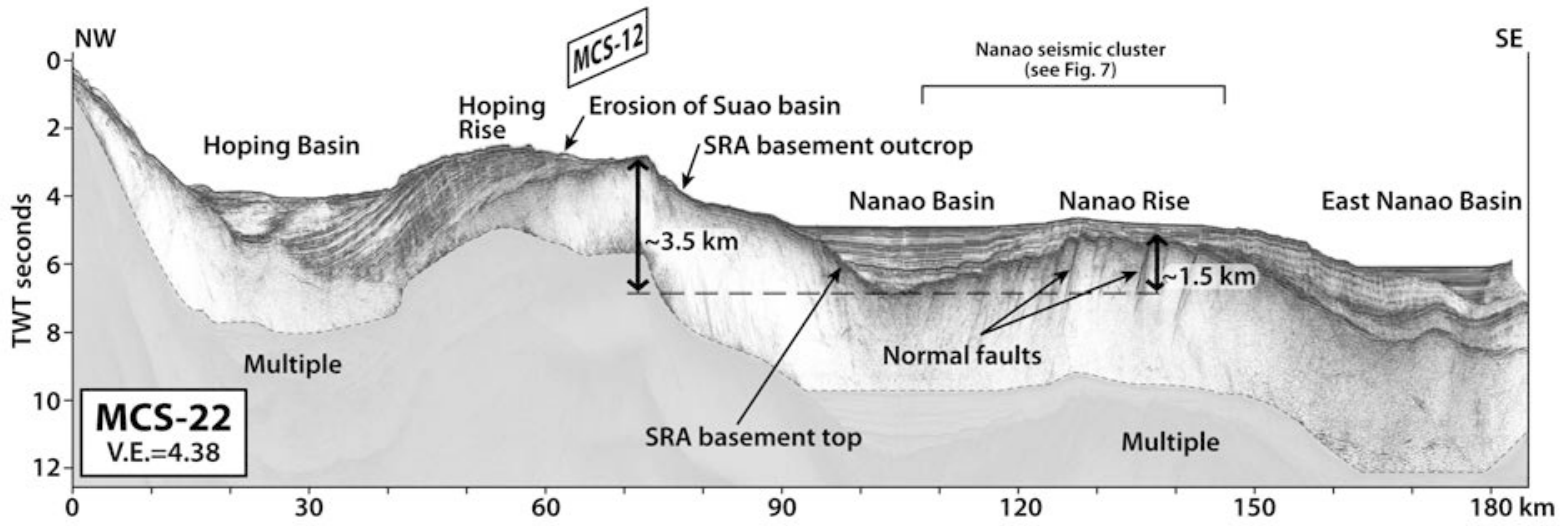

1223

1224

Fig.12

1225 


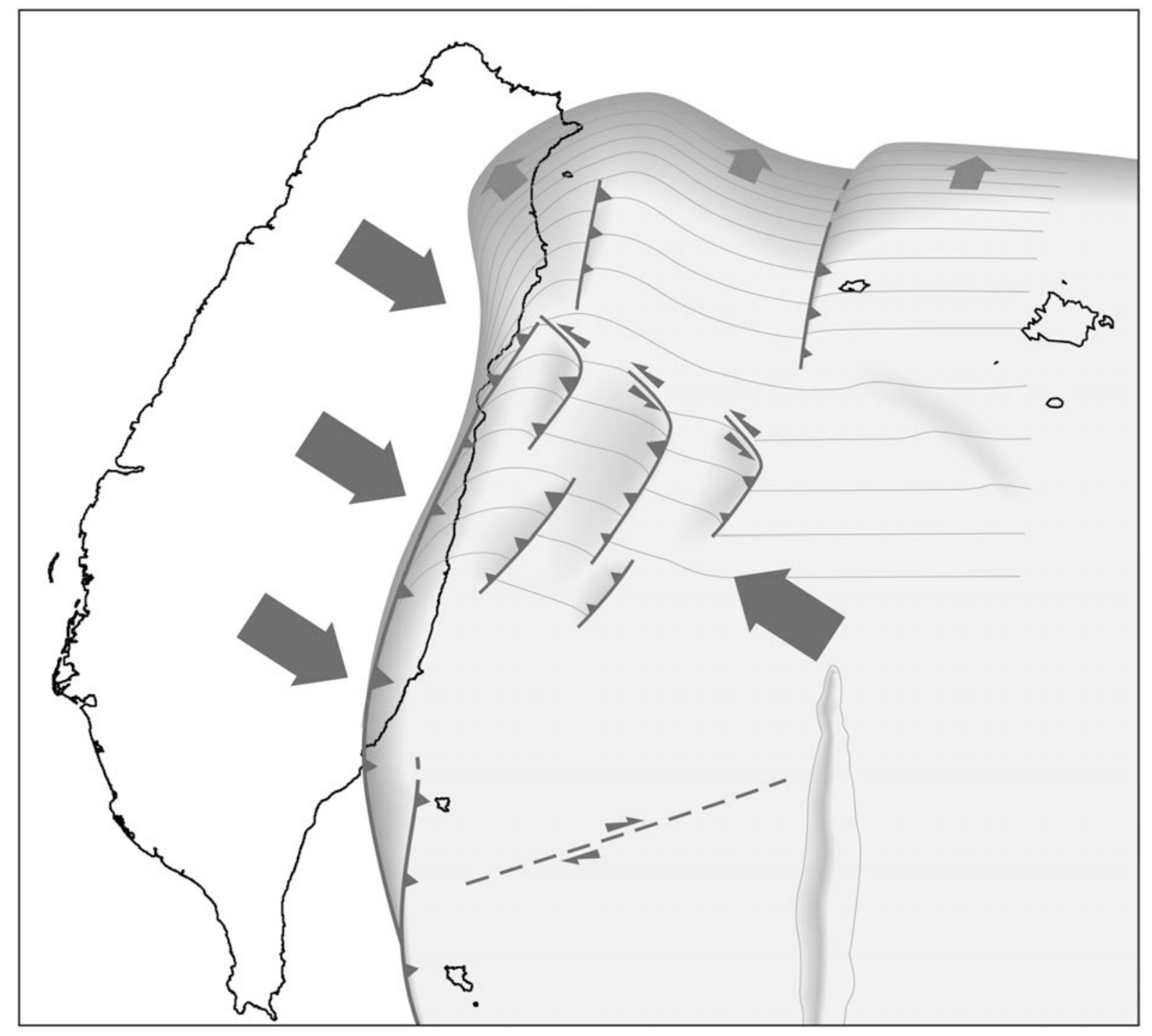

Fig.13 


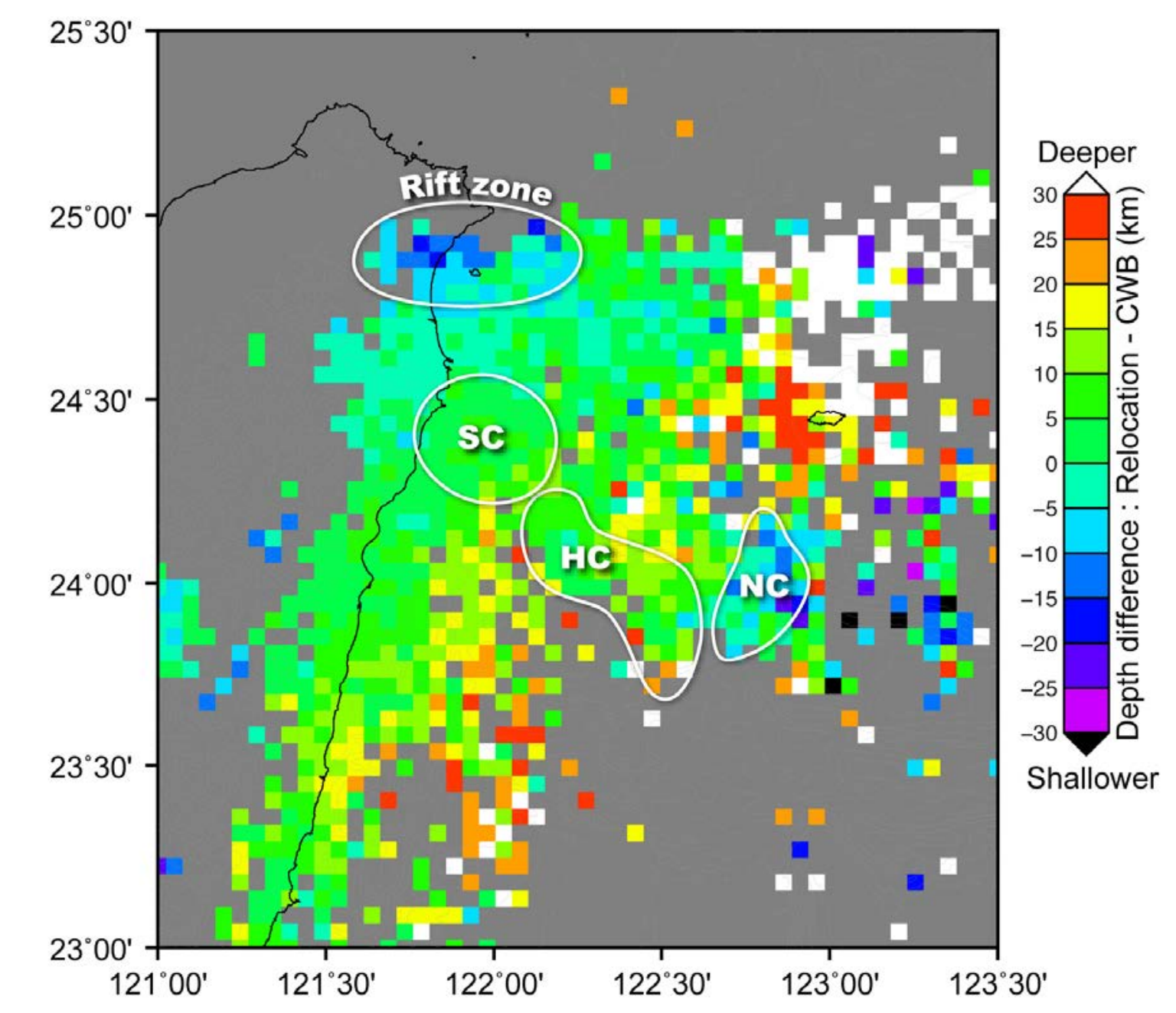




\begin{tabular}{|c|c|c|c|c|c|}
\hline \multirow{2}{*}{$\begin{array}{l}\text { date of event } \\
\text { day/month/year/ } \\
\text { (time) }\end{array}$} & \multicolumn{2}{|c|}{ magnitude } & \multicolumn{2}{|c|}{ estimated depth $(\mathrm{km})$} & \multirow[b]{2}{*}{$\begin{array}{c}\text { prefered source } \\
\text { for focal } \\
\text { mechanism }\end{array}$} \\
\hline & $\begin{array}{l}\text { revised moment } \\
\text { magnitude } \mathrm{M}_{\mathrm{w}} \\
\text { (Theunissen et al., } \\
\text { 2010) }\end{array}$ & $\begin{array}{c}\text { local magnitude } \\
\mathrm{M}_{\mathrm{L}} \text { (Central } \\
\text { Weather } \\
\text { Bureau) }\end{array}$ & $\begin{array}{c}\text { from } \\
\text { Central } \\
\text { Weather } \\
\text { Bureau }\end{array}$ & $\begin{array}{l}\text { this study } \\
\text { otherwise } \\
\text { the origin is } \\
\text { mentioned }\end{array}$ & \\
\hline $10 / 05 / 2008$ & & 5.6 & 25 & 30 & CMT \\
\hline $29 / 02 / 2008$ & & 5.1 & 26 & 27 & $\mathrm{CMT}$ \\
\hline $06 / 09 / 2007$ & 6.2 & 6.6 & 54 & 58 & CMT \\
\hline $16 / 01 / 2007$ & 5.2 & 5.4 & 21 & 25 & CMT \\
\hline $24 / 02 / 2006$ & & 5.2 & 13 & 7 & CMT \\
\hline $23 / 01 / 2006$ & & 4.9 & 18 & 26 & CMT \\
\hline $01 / 06 / 2005$ & 5.4 & 6.0 & 65 & 58 & CMT \\
\hline $16 / 12 / 2004$ & & 5.1 & 9 & 28 & CMT \\
\hline $11 / 11 / 2004$ & 5.6 & 6.1 & 27 & 35 & CMT \\
\hline $08 / 11 / 2004$ & 6.3 & 6.6 & 10 & 24 & CMT \\
\hline $30 / 07 / 2003$ & 5.2 & 5.1 & 12 & 25 & CMT \\
\hline $09 / 06 / 2003$ & 5.8 & 5.7 & 32 & 31 & CMT \\
\hline 01/09/2002-7h07 & 5.3 & 5.5 & 16 & 27 & CMT \\
\hline 01/09/2002-5h56 & 5.4 & 5.5 & 9 & 30 & BATS \\
\hline $22 / 08 / 2002$ & & 4.7 & 33 & 27 & BATS \\
\hline $09 / 08 / 2002$ & & 4.6 & 18 & 28 & BATS \\
\hline $16 / 07 / 2002$ & & 4.1 & 17 & 24 & BATS \\
\hline $20 / 06 / 2002$ & & 4.2 & 3 & 42 & BATS \\
\hline $10 / 04 / 2002$ & & 4.5 & 20 & 27 & BATS \\
\hline $31 / 03 / 2002$ & 7.1 & 6.8 & 14 & 23 & CMT \\
\hline $18 / 12 / 2001$ & 6.8 & 6.7 & 12 & 15 & CMT \\
\hline $14 / 06 / 2001$ & 5.9 & 6.3 & 17 & 22 & CMT \\
\hline $25 / 02 / 2001$ & & 4.7 & 14 & 27 & BATS \\
\hline $16 / 09 / 2000$ & 5.2 & 5.3 & 15 & 23 & CMT \\
\hline $18 / 04 / 2000$ & & 4.6 & 5 & 30 & BATS \\
\hline $14 / 04 / 2000$ & 5.1 & 5.2 & 48 & 62 & BATS \\
\hline 20/09/1999 & 7.6 & 7.3 & 8 & & CMT \\
\hline $22 / 02 / 1999$ & 5.9 & 5.9 & 4 & 29 & CMT \\
\hline 29/07/1996 & 5.4 & 6.1 & 66 & 68 & CMT \\
\hline 29/03/1996 & 5.7 & 5.6 & 6 & 19 & CMT \\
\hline $24 / 05 / 1994$ & 6.5 & 6.6 & 5 & 24 & Kao et al., 1998 \\
\hline $23 / 05 / 1994$ & 6.1 & 5.8 & 7 & 34 & Kao et al., 1998 \\
\hline $14 / 11 / 1986$ & 7.3 & 7.8 & 15 & & Kao et al., 1998 \\
\hline $23 / 12 / 1978$ & 7.0 & 7.0 & 4 & $48-E H B$ & Kao et al., 1998 \\
\hline $24 / 04 / 1972$ & 7.0 & 6.7 & 15 & & Kao et al., 1998 \\
\hline $25 / 01 / 1972$ & 7.3 & 7.0 & 33 & $10-E H B$ & Kao et al., 1998 \\
\hline $12 / 03 / 1966$ & 7.5 & 7.8 & 42 & $29-E H B$ & Kao et al., 1998 \\
\hline $13 / 02 / 1963$ & 7.2 & 7.4 & 47 & $35-E H B$ & Chen et al., 2004 \\
\hline $22 / 10 / 1951$ & 7.0 & 7.2 & 20 & $\begin{array}{c}1 \text { - Cheng et } \\
\text { al., } 1996\end{array}$ & Cheng et al., 1996 \\
\hline $21 / 10 / 1951$ & 7.1 & 7.4 & 9 & $\begin{array}{c}4 \text { - Cheng et } \\
\text { al., } 1996\end{array}$ & Cheng et al., 1996 \\
\hline $05 / 06 / 1920$ & 7.7 & 8.0 & 20 & 25 & see table legend \\
\hline
\end{tabular}

